\title{
Ecosystem-Based and Community-Based Model Integration to Designate Coral Reef No-Take Marine Protected Areas: A Case Study from Puerto Rico
}

\author{
Edwin A. Hernández-Delgado ${ }^{1,2,3 *}$, Manoj Shivlani4, Alberto M. Sabat ${ }^{2}$ \\ ${ }^{1}$ Center for Applied Tropical Ecology and Conservation, Coral Reef Research Group, University of Puerto Rico, \\ San Juan, Puerto Rico \\ ${ }^{2}$ Department of Biology, University of Puerto Rico, San Juan, Puerto Rico \\ ${ }^{3}$ Sociedad Ambiente Marino, San Juan, Puerto Rico \\ ${ }^{4}$ Center for Independent Experts, Northern Taiga Ventures Inc., Miami, USA \\ Email: ${ }^{*}$ edwin.hernandezdelgado@gmail.com
}

Received 3 June 2014; revised 3 July 2014; accepted 12 July 2014

Copyright $@ 2014$ by authors and Scientific Research Publishing Inc.

This work is licensed under the Creative Commons Attribution International License (CC BY).

http://creativecommons.org/licenses/by/4.0/

(c) (i) Open Access

\section{Abstract}

Ecosystem-based management and community-based participation in governance of Marine Protected Areas (MPAs) have been identified as key elements to improve management success, local stakeholder support, and compliance with regulations. However, both are often rarely achieved, resulting in poor MPA governance, support and success. A quantitative assessment of the spatiotemporal change (1997-2012) of coral reef fish communities within Arrecifes La Cordillera Natural Reserve in northeastern Puerto Rico was carried out. We also identified community expectations of and support for the designation of a network of small no-take MPAs within the reserve's boundaries. A holistic approach employing biophysical and socioeconomic methods was used as part of a participatory model to identify priorities for the designation of candidate no-take MPAs. Populations of the most important fishery-targeted species showed a significant temporal decline, particularly in areas subjected to intense recreational activities and spearfishing. Most groupers (Serranidae), snappers (Lutjanidae), barracudas (Sphyraenidae), and some parrotfishes (Scaridae) were nearly absent at most sites. Most individuals belonged to smaller size categories. Herbivores represented the majority of the total fish biomass, suggesting strong fishing impacts on apex predators. Fish declines also occurred after two massive coral bleaching events in 1998 and 2005 that were followed by mass coral mortalities, suggesting combined negative impacts of fishing and climate change. A no-take MPA designation was supported by $80 \%$ of the artisanal fishermen, $73 \%$

${ }^{*}$ Corresponding author.

How to cite this paper: Hernández-Delgado, E.A., Shivlani, M. and Sabat, A.M. (2014) Ecosystem-Based and Community-Based Model Integration to Designate Coral Reef No-Take Marine Protected Areas: A Case Study from Puerto Rico. Natural Resources, 5, 538-560. http://dx.doi.org/10.4236/nr.2014.510049 
of the concessionaires (i.e., SCUBA diving, charter boats), and $52 \%$ of registered vessel operators. Stakeholders agreed that coral reef conditions in the reserve had declined over time, as well as water quality which affected reef health and fisheries. Stakeholders did not recognize climate change and sea surface warming as threats to coral reefs and fisheries. Nonetheless, stakeholder perceptions of candidate no-take MPA sites remarkably matched those identified through fish counts. This study also highlighted the pervasive views held by many stake-holders concerning MPA management and enforcement, and recommended that any no-take MPA designation process considers improving stakeholder participation, understanding of management objectives, actions, and accomplishments, and building stakeholders trust. The integration of ecosystem-based and community-based participatory models may be critical to foster improved support of no-take MPAs and foster a long-term community-based integration to develop and implement mitigation strategies for climate change impacts in novel future scenarios.

\section{Keywords}

\section{Climate Change, Community-Based Management, Fish Communities, Marine Protected Areas}

\section{Introduction}

The designation of no-take Marine Protected Areas (MPAs) has been one of the top priority strategies for the conservation and restoration of coral reef resources, and for recovering depleted reef fisheries at local, regional and global scales [1]-[7]. Recent regional assessments have identified overfishing as a top priority issue through the northeastern Caribbean, including Puerto Rico (PR) [8]-[10]. But MPA designation alone is not enough to protect and recover depleted reef resources from other local human sources of stress besides fishing or from large-scale, climate change related impacts. There is increasing evidence that major fish community decline has occurred following major losses of living coral cover and post-bleaching coral mortality [11]-[14]. Therefore, reef managers are in need of improved strategies to select and design adequate, representative and functional notake MPAs, but also to complement them with policies aimed at reducing the activities responsible for climate change [14]. There is also evidence that MPA success is highly associated to strong governance and enforcement, successful implementation of a management plan, and full participation and support of local base communities through a co-management model, but less than 20\% of Caribbean MPAs in 2003 were fully compliant [15].

The Commonwealth of PR supports 38 MPAs, covering 416,329 ha of benthic habitat, of which only five (11,049 ha) are full-time no-take MPAs under the Commonwealth Jurisdiction (2.6\%) and 9,169 ha (2.2\%) have partial (seasonal) closures and are under US Federal Jurisdiction [16] [17]. This means that only $4.8 \%$ of the current MPA system in PR is no-take reserves. With the exception of Canal Luis Peña No-Take Natural Reserve, in Culebra Island, and Isla Verde Marine Reserve, in Carolina, which were designated with direct community-based participation, the remaining 36 MPAs were designated through standard government-driven, top-down processes with very limited public participation. Further, MPA designation processes in PR have not followed a uniform protocol, with some being designated under the Commonwealth Fishery Law and others by legislative action. As a result, scientific criteria, as well as baseline quantitative information regarding the status of their natural resources, have been significantly scarce for many of them. Community-based participation and support have also been very limited. Commercial fishery landings in PR have declined by approximately $85 \%$ between 1979 and 2007, which has led to a decline in fishing efforts [18]. Previous studies in PR have also shown declining trends in fish communities within MPAs with declining water quality and reef condition [19] [20]. However, there is still limited information regarding the status of coral reef-associated fisheries within many of the MPAs in PR, including the high-priority area of Arrecifes La Cordillera Natural Reserve (ALCNR), off northeastern PR. Significant fishing impacts across several locations within ALCNR have already been documented [19] [21], but management actions to reverse those impacts have not been implemented yet.

Several indicators have been suggested as measures of MPA effectiveness, including a functional protected status, full-time personnel, patrol boat, regular patrolling and enforcement, buoys and signs, sustained funding 
support by local government, functional management by local government or co-management in partnership with local communities and interested stakeholders, at least a moderate fish biomass (i.e., $200 \mathrm{~kg} / \mathrm{ha}$ ) and high fish density and biodiversity, at least a "fair" live hard coral-seagrass-mangrove cover ( $>25 \%)$, and a Catch Per Unit Effort (CPUE) of at least $1.0 \mathrm{~kg} /$ person/h for hook-and-line fishing outside the reserve [22]. But for most MPAs in PR there is limited information regarding the status of their reef fishery resources, and lack full-time management and enforcement personnel, and an enforceable management plan. Further, ecosystem-based reef fishery management has been rarely implemented and community-based participatory processes have remained largely absent, resulting in very limited public support. Therefore, the designation of future no-take MPAs requires novel interdisciplinary and participatory approaches.

This study provides a quantitative baseline regarding the status of reef fisheries within ALCNR across a 15-year time span (1997-2012) and identifies the community expectations of and support for the designation of no-take MPAs within the reserve boundaries. We used a holistic approach that employed a set of biophysical and socioeconomic methods as part of a participatory model to develop a set of interdisciplinary criteria necessary for the establishment of priorities for the identification of candidate no-take MPAs. This project was aimed at achieving the following three objectives: 1) quantitatively assess the status of coral reef fish communities within ALCNR; 2) develop a participatory model to involve local fisher communities and other stakeholder groups in a decision-making process aimed at evaluating the condition of reef habitats and fisheries, and at suggesting candidate no-take MPA sites within ALCNR; and 3) develop an interdisciplinary data matrix using a combination of biological, ecological, regional, impacts, pragmatic, social, and economic criteria to rank no-take MPA sites. This allowed a novel integration of ecosystem-based and community-based models. The results identified areas of convergence between different stakeholder groups, ranked candidate no-take MPA sites, evaluated the preferred methods of public participation within and between community groups, and determined community expectations of no-take MPA benefits and costs. Furthermore, the information gathered contributed to devising and prioritizing strategies by which to maximize coral reef-associated fisheries protection while enabling public participation and maximizing community support for no-take MPAs.

\section{Materials and Methods}

\subsection{Study Site}

The study was carried out across seven sites within ALCNR, located 3 - 11 km off Fajardo, northeastern PR (Figure 1). These included from east to west: Cayo Diablo (DIA), Sur de Pando (SDP), Palominos Island (PLM), Palominitos Island (PLT), Cayo Lobos (LOB), Cayo Icacos-East (ICAE), and Cayo Icacos-West (ICAW). ALCNR was designated in 1980 and managed by the PR Department of Natural and Environmental Resources (PRDNER). Fishing is allowed across the entire reserve.

\subsection{Spatio-Temporal Patterns in Fish Community Structure}

Fish communities were sampled at three of the sites that had fish community data from previous years at following a three-way factorial design with time $(1997,2007,2012)$, sites (ICA east, PLT, DIA) and depth zones (I $\leq 5 \mathrm{~m}, \mathrm{II}=5-15 \mathrm{~m}$ ) as main factors. Although fish surveys were conducted during 2007 across all sites as part of the multi-criteria evaluation, only data from these three sites were analyzed for spatio-temporal patterns. Only shallow depth zones were sampled at ICA. Variable replicate fish censuses were conducted in $1997(\mathrm{n}=11-21)$, but only 5 per depth zone/site were conducted in 2007 and 2012. Fishes were identified to the lowest taxon possible, counted and fork length estimated for each individual through $30 \times 4 \mathrm{~m}$ belt transects. Fish fork length data was used to calculate biomass [23]. Data analyzed in this study was based in biomass calculations. Also, species richness, cumulative dominance, species diversity index (H'n) [24], and evenness (J'n) [25] were calculated. Temporal and spatial variation patterns in coral reef fish community structure and parameters were tested using a three-way permutational analysis of variance (PERMA-NOVA) using multivariate statistical package PRIMER-e v.6.1.16 + PERMANOVA v.1.0.6 [26] [27]. Principal Component Ordination (PCO) was used to determine fish community spatial clustering patterns, and determine which fish species and fish functional groups better described observed patterns. SIMPER routine was used to confirm indicator species of observed spatiotemporal patterns in fish community structure. Bubble plots based on Bray-Curtis ordination [28] and non-linear Multi-Dimensional Scaling (MDS) analyses were used to determine temporal trends in biomass of key fishery 


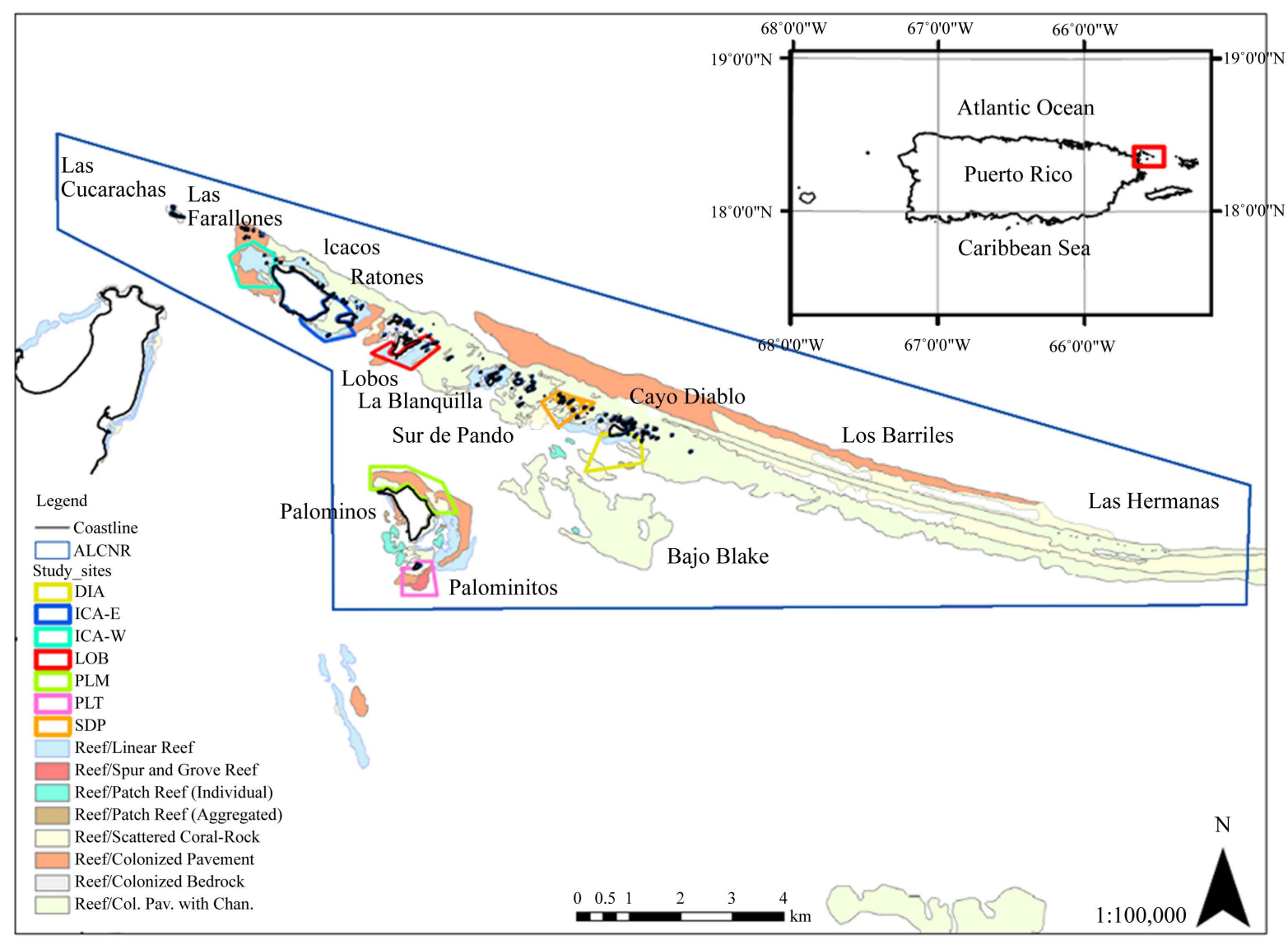

Figure 1. Study sites at Arrecifes La Cordillera Natural Reserve, Fajardo, PR.

targeted species [26]. Fish biomass data were $\sqrt{ }$-transformed, while species richness, H'n, and J'n data were $\log _{10}$-transformed. All multivariate tests were conducted using 10,000 permutations.

\subsection{Community-Based Participatory Model}

We developed a participatory model to involve local fisher communities and other stakeholder groups in a decision-making process aimed at identifying and recommending no-take MPA sites within ALCNR. This was achieved by conducting surveys and semi-structured interviews with key informants from each stakeholder group. The stakeholder groups identified in the study consisted of those that participated in consumptive activities, such as fishing, and those that participated in non-consumptive activities, as related to recreation. The three main groups identified as part of the scoping session were commercial fishing operators $(\mathrm{n}=12)$, dive charters and pleasure (mixed) trip charters $(n=16)$, and private vessel operators $(n=102)$.

The approaches adopted for each of the groups varied. Key informants among commercial fishermen were identified via previous research in the area [29]. This included discussions with the "Villa Pesquera" (fish house) fishery leaders from the adjacent Fajardo and Ceiba municipalities, with assistance from the PRDNER's Fisheries Research Laboratory field data collector (J. León, personal communication). Additional interviews were conducted with commercial fishermen from adjacent ports (Luquillo to Río Grande to the north, and Patillas to the south) to ensure that those communities did not fish within the reserve. With concessionaires, ALCNR personnel provided the names and locations of all dive and pleasure trip charters authorized to take out clients into the reserve, and these were located mainly in two marinas: Villa Marina and Puerto del Rey in Fajardo. Unlike as with the key informant approach used for commercial fishermen, a census approach was adopted for reserve concessionaires. With both commercial fishermen and reserve concessionaires, semi-structured interviews were utilized in conjunction with a specific survey instrument.

Respondents were interviewed about particular issues related to candidate no-take MPA sites, their views on 
MPA managements, and their preferences towards management authority via open-ended questions. Use patterns and resources trend analysis were collected using a formal survey instrument. To sample the large population of private vessel operators, a self-administered intercept survey was developed that was passed out by all of the personnel working at the Puerto del Rey marina vessel registration office to vessel operators either registering a vessel or renewing a registration. The office was selected because most of the vessels that register at the office operate in eastern PR, of which many visit the reserve. Commercial fishermen were interviewed using both a survey instrument and open-ended questions from August 2007 to June 2008 in three fish houses in Fajardo and one in Ceiba. Similarly, dive operations and pleasure trip charters were interviewed using both a survey instrument and open-ended questions, and that survey session lasted from August 2007 to November 2008. Finally, the Puerto del Rey vessel registration office passed out vessel operator surveys from September 2007 to February 2008, over a six-month session.

\subsection{Multi-Criteria Data Matrix to Evaluate Candidate No-Take MPA Sites}

An interdisciplinary data matrix, using a combination of biological, ecological, regional, impacts, pragmatic, economic, and social criteria, was developed to rank priority candidate no-take MPA sites within ALCNR (Table 1). Most of the proposed criteria definitions were based on or modified after [33]. Information was obtained from literature reviews, field surveys (Hernández-Delgado, unpub. data), interviews with stakeholders, and other sources. A 2-point scale was used to score each criteria based on the rankings of each parameter (i.e., fish biomass) as follows: 0 = Low priority site (lower 33\% ranking); 1 = Moderate priority site (middle 33\% - 66\% ranking); 2 = Highly recommended site (upper 66\% - 100\% ranking). Candidate no-take MPA sites within ALCNR were ranked according to the global scores from the matrix.

\section{Results}

\subsection{Spatio-Temporal Variation in Fish Diversity}

Coral reef fish communities within ALCNR were showing unequivocal signs of crisis. Figure 2 shows spatiotemporal patterns in fish community parameters. Species richness showed a highly significant difference among years and sites, but not between depth zones (Table 2). All interaction effects were significant. Observed patterns showed a trend of increasing species richness with time following impacts of two massive coral reef bleaching events followed by mass coral mortality in 1998 and 2005. The pattern is also consistent with a major decline in top predator species. DIA-II showed the highest species richness per count (17.9) during 1997 and PLT-I the lowest (14.5). During 2007 the pattern was similar, with DIA-II having 21.0/count and PLT-I 14.4. During 2012 DIA-II showed the highest species richness with 25.4/count, while ICA had 16/count. Species diversity index (H'n) showed a highly significant difference among years and sites, but not between depth zones (Table 3). All interaction effects were significant. Observed patterns showed a similar temporal trend of increasing fish H'n following major disturbance by bleaching and coral mortality, and following a major decline in top predator species. During 1997 DIA-II showed the highest H'n (2.611) and PLT-II the lowest (2.4150). During 2007 DIA-II had 2.7610 and ICA 2.4727. During 2012, H'n was 2.9878 at DIA-II, and 2.5939 at ICA. Species evenness (J'n) showed also a highly significant difference among years and sites, but not between depth zones (Table 4). All interaction effects, except Site $\times$ Depth, were significant. Observed J'n patterns showed also a temporal trend of increase following bleaching and coral mortality, and following a major decline in top predator species. During 1997 PLT-I showed the highest J'n (0.9165) and ICA the lowest (0.8816). During 2007 PLT-I had 0.9366 and DIA-II0.9138. During 2012, J'n was 0.9549 at PLT-I, and 0.9262 at DIA-II.

\subsection{Spatio-Temporal Variation in Fish Biomass}

There was a highly significant difference in total fish biomass among years and across sites, and between depth zones (Table 5). All interaction effects were also significant. Observed patterns often resulted in a declining trend through time across most sites. The highest total biomass in 1997 was observed at ICA (682 kg/ha), with the lowest at PLT-I (156 kg/ha). During 2007, DIA-II had $293 \mathrm{~kg} / \mathrm{ha}$ and PLT-I 113 kg/ha. During 2012, DIA-II had $302 \mathrm{~kg} / \mathrm{ha}$, and ICA only 110. The magnitude of total fish biomass decline between 1997 and 2012 was 84\% at ICA, $26 \%$ at PLT-I, $42 \%$ at DIA-I, and $40 \%$ at DIA-II. Only PLT-II showed a $20 \%$ increase in fish biomass, in comparison to 1997, mostly as a result of increasing biomass of non-target species (i.e., Pomacentridae), sug- 
Table 1. Multi-criteria data matrix for the evaluation of candidate no-take MPA sites.

\begin{tabular}{|c|c|}
\hline Criteria & Description \\
\hline Biological & $\begin{array}{l}\text { Based on the following parameters: 1) Fish species richness; 2) H’n; 3) J’n; 4) Total fish abundance; 5) Total herbivore } \\
\text { abundance; 6) Non-denuder abundance; 7) Browser abundance; 8) Scraper abundance; 9) Omnivore abundance; 10) Total } \\
\text { carnivore abundance; 11) Generalists abundance; 12) Planktivore abundance; 13) Piscivore abundance; 14) Fishery target } \\
\text { abundance; 15) Total biomass; 16) Total herbivore biomass; 17) Non-denuder biomass; 18) Browser biomass; 19) Scraper } \\
\text { biomass; 20) Omnivore biomass; 21) Total carnivore biomass; 22) Generalists biomass; 23) Planktivore biomass; 24) } \\
\text { Piscivore biomass; 25) Fishery target biomass; and 26) Reef substrate heterogeneity index (RSHI). Absolute values of each } \\
\text { single parameter were individually ranked and classified in several ranking categories using GIS. }\end{array}$ \\
\hline Ecological & 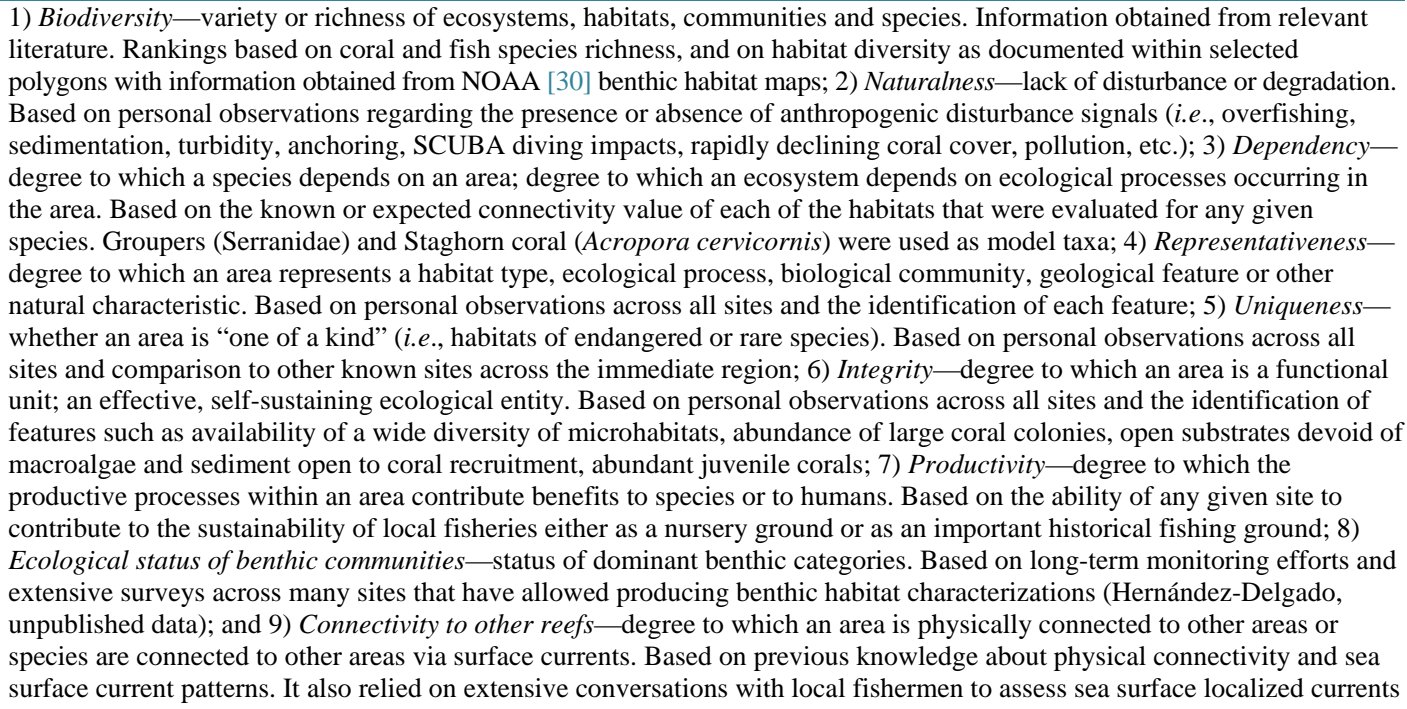 \\
\hline
\end{tabular}
patterns.

1) Regional significance - degree to which an area represents a characteristic of the region; and 2) Sub-regional significance

Regional - degree to which an area fills a gap in the network of protected areas from the sub-regional perspective. This analysis was based on previous knowledge of the relevant literature and of existing MPA networks across the northeastern Caribbean region (i.e., biodiversity information available from different sources, including http://www.reefbase.org).

1)Vulnerability - area's susceptibility to degradation by natural events or the activities of people; 2) Degree of threatpresent and potential threats from direct exploitation and development projects; and 3) Evident overfishing effects—area

Impacts showing signs of low fish abundance, small size classes, low predator populations, impacts of fishing gear, etc. Scores were based on ranks obtained during this study, in combination with previous knowledge and the available literature.

1) Urgency — degree to which immediate action must be taken and values within the area be transformed or lost; 2) Sizedegree to which various habitats need to be included in the protected area as an integrated ecological unit; 3) Effectivenessfeasibility of implementing a management program; 4) Opportunism — degree to which existing conditions or actions already

Pragmatic under way or a ground swell of popular support may justify further action; 5) Availability — degree to which the area can be managed satisfactorily; and 6) Restorability — degree to which an area may be returned to its former natural state, increase in productivity or value to important species and processes. Pragmatic criteria scores were based in previous knowledge by authors and also in different interviews with DNER personnel.

1) Importance to species - degree to which certain commercially important species depend on an area; 2) Importance to fisheries - number of dependent fishermen and/or size of the fishery yield; degree to which an area plays an important link to fisheries; 3) Nature of threats - extent to which changes in use patterns threaten the overall value; 4) Economic benefits-

Economic degree to which protection will affect the local economy in the long term; and 5) Tourism-existing or potential value of an area to tourism activities. Scoring of economic criteria was dependent on a combination of user's perceptions, opinions and experience by DNER personnel, on previous knowledge and experience by the authors, and on recent data [31] [32].

1) Social acceptance — degree to which the support of local people is assured; 2) Recreation — degree to which the area is, or could be used for recreation; 3) Culture - religious, historic, artistic, or other cultural value of the site; 4) Aesthetics-a seascape, landscape, or other area of exceptional scenic beauty; 5) Conflicts of interest - degree to which area protection would affect the activities of local residents (i.e., artisanal fishermen); 6) Safety-degree of danger to people from strong currents, surf, submerged obstacles, waves, and other hazards; 7) Accessibility - the ease of access across sea; 8) Research and education - degree to which an area represents various ecological characteristics and can serve for research and

Social demonstration of management and scientific methods; 9) Public awareness-degree to which monitoring, research, education, or training the area can contribute knowledge and appreciation of the importance of conservation of marine resources; 10) Conflict and compatibility — degree to which an area may help to resolve conflicts between natural resource values and human activities, or the degree to which compatibility between them may be enhanced; and 11) Benchmarkdegree to which the area may serve as a "control site" for scientific research (i.e., a largely undisturbed site in which natural processes can proceed without manipulation and which can be used to measure changes elsewhere). Scoring of social criteria was dependent on user's perceptions, experience by DNER's personnel, on authors' experience, and the literature. 

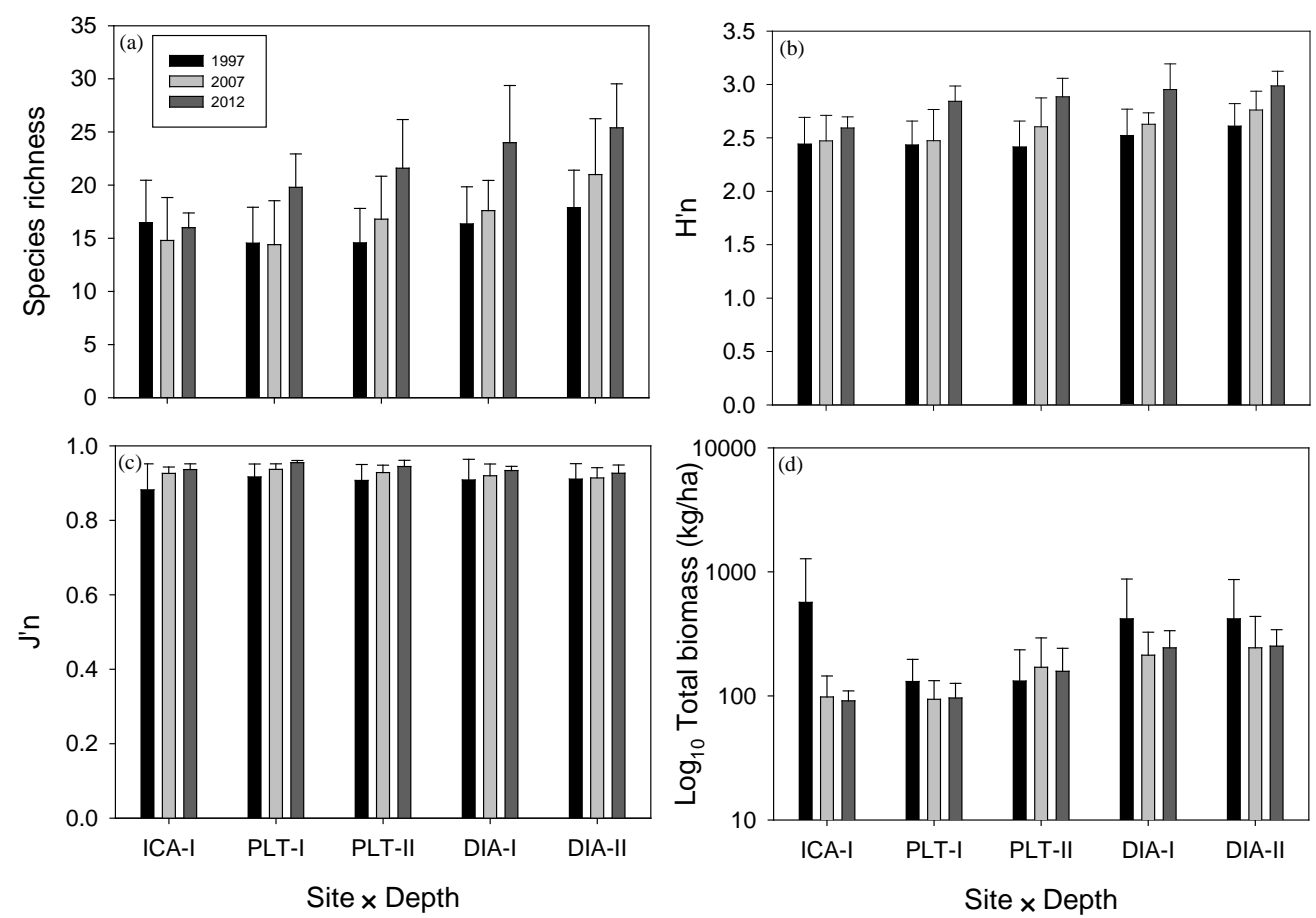

Figure 2. Spatio-temporal patterns in fish community parameters. From top left: (a) Species richness; (b) Species diversity index (H’n); (c) Evenness (J’n); and (d) Total fish biomass (kg/ha). Data: mean \pm 95\% confidence intervals.

Table 2. Three-way PERMANOVA analysis of spatio-temporal variation in fish species richness (S).

\begin{tabular}{cccccccc}
\hline Criteria & d.f. & Pseudo-F & $\boldsymbol{P}$ & Pairwise Time & t & $\boldsymbol{P}$ \\
\hline Time & 2126 & 15.09 & $<0.0001$ & 1997 vs 2007 & 0.94 & 0.3533 \\
Site & 2126 & 9.23 & 0.0003 & 1997 vs 2012 & 5.63 & $<0.0001$ \\
Depth & 1127 & 1.82 & 0.1800 & 2007 vs 2012 & 3.62 & 0.0011 \\
Time $\times$ Site & 8120 & 8.71 & $<0.0001$ & Pairwise Site & $\mathbf{t}$ & $\boldsymbol{P}$ \\
Time $\times$ Depth & 5123 & 7.81 & $<0.0001$ & ICA vs PLT & 0.34 & 0.7442 \\
Site $\times$ Depth & 4124 & 4.90 & 0.0011 & ICA vs DIA & 3.18 & 0.0019 \\
Time $\times$ Site $\times$ Depth & 14,114 & 5.30 & $<0.0001$ & PLT vs DIA & 4.01 & $<0.0001$ \\
\hline
\end{tabular}

Table 3. Three-way PERMANOVA analysis of spatio-temporal variation in fish species diversity (H’n).

\begin{tabular}{|c|c|c|c|c|c|c|}
\hline Criteria & d.f. & Pseudo-F & $\boldsymbol{P}$ & Pairwise Time & $\mathbf{t}$ & $\boldsymbol{P}$ \\
\hline Time & 2126 & 26.01 & $<0.0001$ & 1997 vs 2007 & 2.11 & 0.0416 \\
\hline Site & 2126 & 8.08 & 0.0008 & 1997 vs 2012 & 7.18 & $<0.0001$ \\
\hline Depth & 1127 & 1.79 & 0.1794 & 2007 vs 2012 & 4.52 & $<0.0001$ \\
\hline Time $\times$ Site & 8120 & 10.62 & $<0.0001$ & Pairwise Site & $\mathbf{t}$ & $\boldsymbol{P}$ \\
\hline Time $\times$ Depth & 5123 & 11.84 & $<0.0001$ & ICA vs PLT & 0.88 & 0.3734 \\
\hline Site $\times$ Depth & 4124 & 4.21 & 0.0024 & ICA vs DIA & 3.91 & 0.0002 \\
\hline Time $\times$ Site $\times$ Depth & 14,114 & 6.21 & $<0.0001$ & PLT vs DIA & 3.11 & 0.0041 \\
\hline
\end{tabular}


Table 4. Three-way PERMANOVA analysis of spatio-temporal variation in fish species evenness (J'n).

\begin{tabular}{ccccccc}
\hline Criteria & d.f. & Pseudo-F & $\boldsymbol{P}$ & Pairwise Time & t & $\boldsymbol{P}$ \\
Time & 2126 & 9.53 & $<0.0001$ & 1997 vs 2007 & 2.30 & 0.0243 \\
Site & 2126 & 3.40 & 0.0034 & 1997 vs 2012 & 3.75 & 0.0003 \\
Depth & 1127 & 0.11 & 0.7515 & 2007 vs 2012 & 2.78 & 0.0079 \\
Time $\times$ Site & 8120 & 3.87 & 0.0016 & Pairwise Site & t & $\boldsymbol{P}$ \\
Time $\times$ Depth & 5123 & 4.18 & 0.0027 & ICA vs PLT & 2.42 & 0.0164 \\
Site $\times$ Depth & 4124 & 2.08 & 0.0830 & ICA vs DIA & 1.68 & 0.0991 \\
Time $\times$ Site $\times$ Depth & 14,114 & 2.18 & 0.0163 & PLT vs DIA & 0.96 & 0.3508 \\
\hline
\end{tabular}

Table 5. Three-way PERMANOVA analysis of spatio-temporal variation in total fish biomass.

\begin{tabular}{|c|c|c|c|c|c|c|}
\hline Criteria & d.f. & Pseudo-F & $\boldsymbol{P}$ & Pairwise Time & $\mathbf{t}$ & $\boldsymbol{P}$ \\
\hline Time & 2126 & 11.47 & $<0.0001$ & 1997 vs 2007 & 2.97 & $<0.0001$ \\
\hline Site & 2126 & 9.83 & $<0.0001$ & 1997 vs 2012 & 2.52 & $<0.0001$ \\
\hline Depth & 1127 & 4.87 & $<0.0001$ & 2007 vs 2012 & 0.86 & 0.6284 \\
\hline Time $\times$ Site & 8120 & 4.35 & $<0.0001$ & Pairwise Site & $\mathbf{t}$ & $\boldsymbol{P}$ \\
\hline Time $\times$ Depth & 5123 & 4.43 & $<0.0001$ & ICA vs PLT & 2.44 & $<0.0001$ \\
\hline Site $\times$ Depth & 4124 & 3.92 & $<0.0001$ & ICA vs DIA & 1.97 & $<0.0001$ \\
\hline Time $\times$ Site $\times$ Depth & 14,114 & 3.47 & $<0.0001$ & PLT vs DIA & 2.10 & $<0.0001$ \\
\hline
\end{tabular}

gesting a potential indirect cascading effect as a result of declining populations of apex predator species. Increases in Pomacentrids could have also been related to the massive decline in percent living coral cover as a result of post-bleaching mortality events in 1998 and 2005.

\subsection{Spatio-Temporal Variation in Fish Community Structure}

There was a highly significant change in fish community structure through time, across sites, and across depth zones (Table 6). Temporal change between 1997 and 2007, and between 1997 and 2012, was highly significant, but not between 2007 and 2012. All interactions were also highly significant. These results suggest that reef communities underwent significant change within the period of 1997 to 2007 when two significant sea surface warming episodes were followed by two massive coral bleaching events, and two mass coral mortality events. A species cumulative dominance plot (Figure 3(a)) showed a significant decline in cumulative dominance with time as a result of significant declines in dominant species, mostly fishery-targeted taxa. Principal Component Ordination (PCO) analysis (Figure 3(b)) showed that temporal variation in fish community structure at ICA in 1997 was the result of variation in herbivores Acanthurus coeruleus and juvenile stages of Sparisoma sp., planktivores Abudefduf saxatilis and Thalassoma bifasciatum, and corallivore Chaetodon capistratus. Increasing biomass of territorial damselfishes Stegastes leucostictus and Microspathodon chyrurus explained the difference in 2007 and 2012. This solution explained 44\% of the observed variation. PCO analysis at PLT (Figure 3(c)) showed that 1997 patterns were explained by herbivores Scarus vetula (which is also an important fishery-targeted species) and Sp. aurofrenatum, and by C. capistratus. Patterns observed in 2007 were explained by A. coreuleus, St. leucostictus, St. diencaeus, and Sc. iserti. Patterns documented in 2012 were explained by pelagic piscivore Carangoides ruber, and by benthic invertivores Holocentrus adscensionis and Halichoeres bivittatus. This solution explained 33\% of the observed variation. Patterns at DIA were explained in 1997 by C. ruber, A. saxatilis, Sp. viride, Ha. pictus, and St. partitus. Patterns in 2007 were explained by Ha. bivittatus, St. leucostictus, and St. variabilis, while in 2012 by Sp. aurofrenatum, and piscivore Ocyurus chrysurus, a highly fishery-targeted species. This solution explained 29\% of the observed variation. Most of these indicator species were indeed non-targeted taxa. 
Table 6. Three-way PERMANOVA analysis of spatio-temporal variation in fish community structure.

\begin{tabular}{cccccccc}
\hline Criteria & d.f. & Pseudo-F & $\boldsymbol{P}$ & Pairwise Time & t & $\boldsymbol{P}$ \\
Time & 2126 & 6.97 & $<0.0001$ & 1997 vs 2007 & 2.69 & $<0.0001$ \\
Site & 2126 & 5.83 & $<0.0001$ & 1997 vs 2012 & 2.92 & $<0.0001$ \\
Depth & 1127 & 5.30 & $<0.0001$ & 2007 vs 2012 & 0.97 & 0.5109 \\
Time $\times$ Site & 8120 & 4.95 & $<0.0001$ & Pairwise Site & t & $\boldsymbol{P}$ \\
Time $\times$ Depth & 5123 & 4.57 & $<0.0001$ & ICA vs PLT & 2.62 & $<0.0001$ \\
Site $\times$ Depth & 4124 & 4.40 & $<0.0001$ & ICA vs DIA & 2.10 & $<0.0001$ \\
Time $\times$ Site $\times$ Depth & 14,114 & 3.64 & $<0.0001$ & PLT vs DIA & 2.45 & $<0.0001$ \\
\hline
\end{tabular}

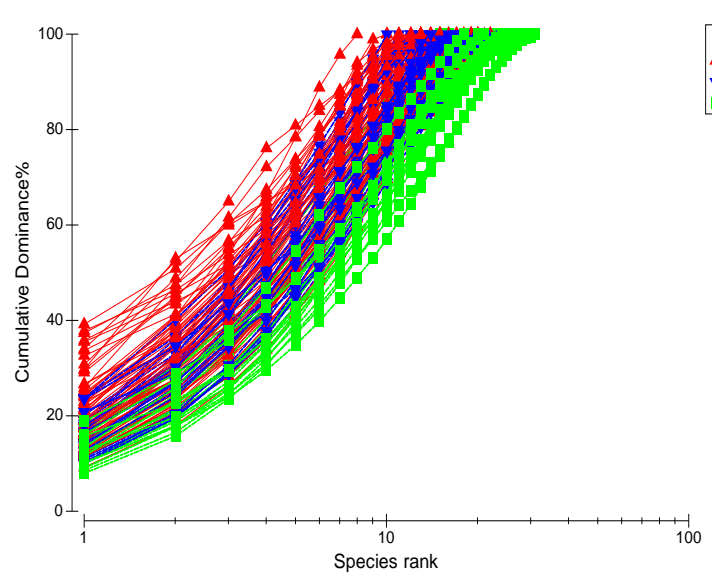

(a)

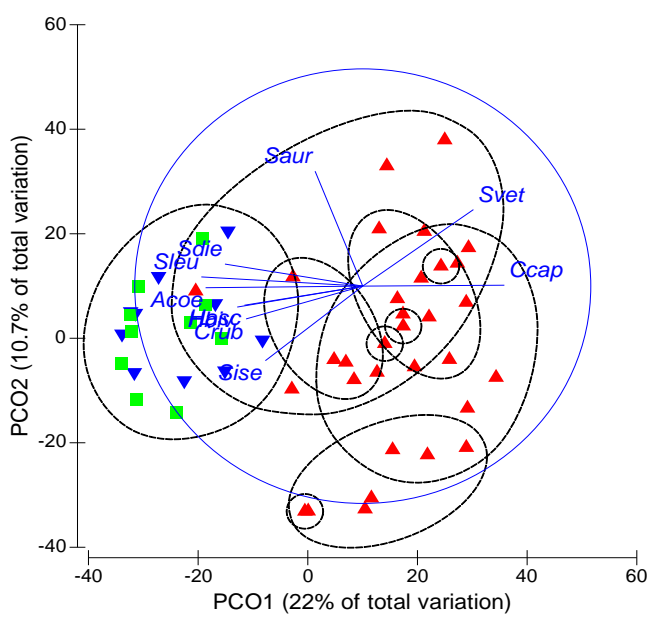

(c)
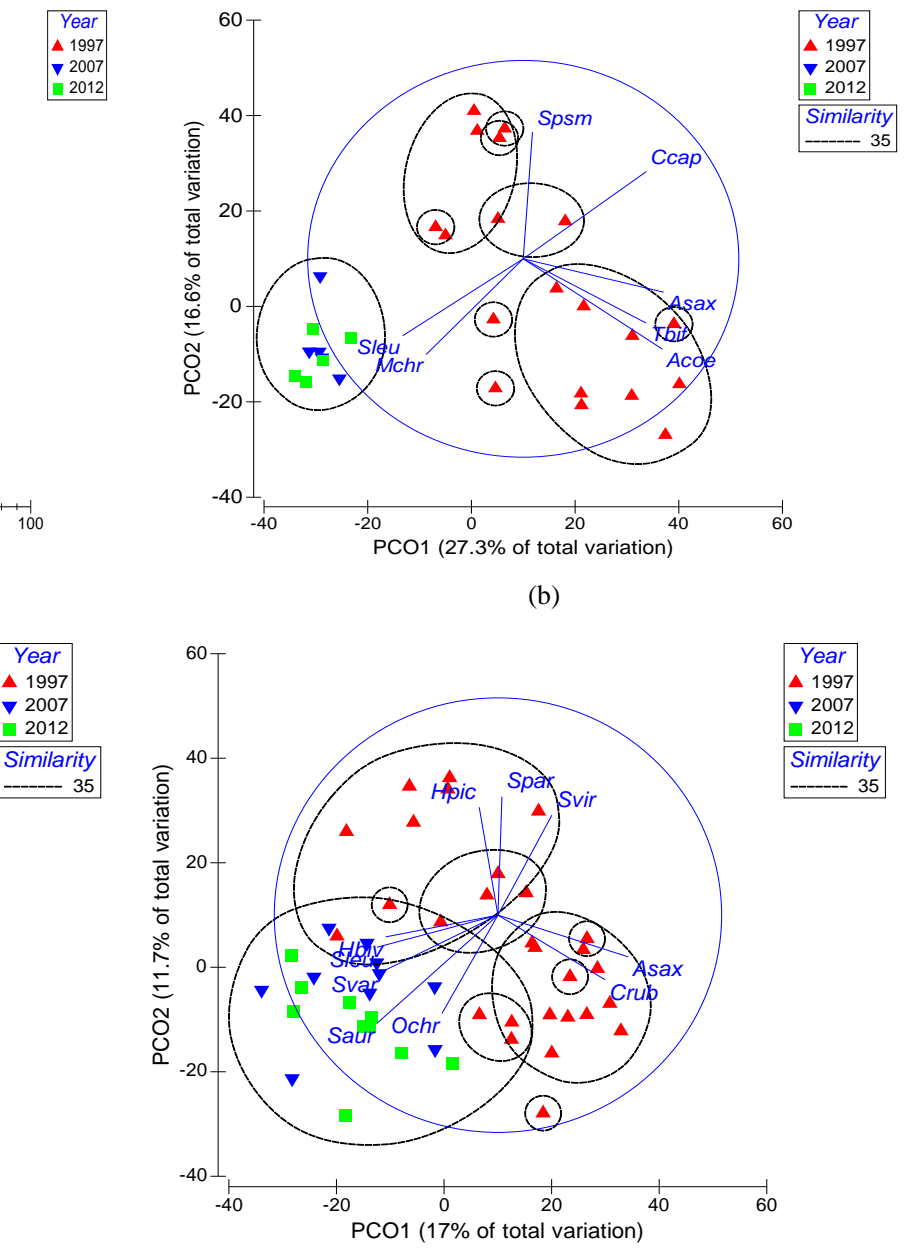

(d)

Figure 3. (a) Species cumulative dominance plot; (b)-(d) Principal component ordination (PCO) analysis of spatio-temporal variation in fish community structure: (b) ICA; (c) PLT; and (d) DIA. Vector analysis was based on minimum correlations of 0.60 .

\subsection{Spatio-Temporal Variation in Fish Dominance}

SIMPER analysis based on fish biomass showed that the top five indicator species of 1997 reefs at ALCNR were Sparisoma viride (18.5\%), Acanthurus coeruleus (12.8\%), Ocyurus chrysurus (8.3\%), Abudefduf saxatilis (7.9\%), and Chaetodon capistratus (6.5\%), with a cumulative contribution of 54\%. Average similarity of all reefs surveyed was 33\%. The top five indicator species of 2007 were Sp. aurofrenatum (16\%), Ac. bahianus 
(14.3\%), Sp. viride (12.8\%), Ac. coeruleus (12.7\%), and Scarus iserti (7.8\%), with a cumulative contribution of $63.5 \%$. Average similarity of all reefs surveyed was $46 \%$. The top five indicator species of 2012 were Ac. coeruleus (12.4\%), Sp. aurofrenatum (10.1\%), Sp. viride (9.8\%), Ac. bahianus (9.6\%), and Microspathodon chrysurus (7\%), with a cumulative contribution of $48.9 \%$. Average similarity of all reefs surveyed was $54 \%$. Differences between 1997 and 2007 were mostly explained by declining schools of browser herbivore Ac. coeruleus and of planktivore $A b$. saxatilis. Declining abundance of Ac. coeruleus also explained differences between 1997 and 2012. The reappearance of $O$. chrysurus, particularly at PLT and DIA, did explain most of the variation between 2007 and 2012. Average dissimilarity between 1997 and 2007 was 70\%, and between 1997 and 2012 was 69\%. Average dissimilarity between 2007 and 2012 was 49\%.

Observed temporal trends showed that fish communities were becoming more similar across sites and that observed gradients in piscivore and generalist predator abundance in 1997 were rapidly lost after the 1998 and 2005 massive bleaching and mass coral mortality events, and following 15 years of continuing fishing impacts. Dominant fish species (by biomass) at ICA were Ac. coeruleus and Sp. viride, while Sp. viride and Ocyurus chrysurus were dominant at PLT, and Sp. viride and Ac. coeruleus were dominant at DIA, with overall similarity averaging 36\% across sites. Higher abundance of Ac. coeruleus at ICA explained most of the difference observed between ICA and PLT (73\% dissimilarity), and between ICA and DIA (69\% dissimilarity). Higher abundance of $A b$. saxatilis at DIA explained most of the difference between PLT and DIA (71\% dissimilarity).

\subsection{Decline in Fishery-Targeted Species}

There is significant evidence that critical fishery-targeted species showed significant signs of decline through time across most sites (Figure 4). Important targeted members of groupers (subfamily Epinephelinae) basically disappeared after 1997 from most sites, including the Red Hind (Epinephelus guttatus), Rock Hind (E. adscensionis), Nassau grouper (E. striatus), and Coney (Cephalopholis fulva). No critically-depleted Goliath grouper (E.

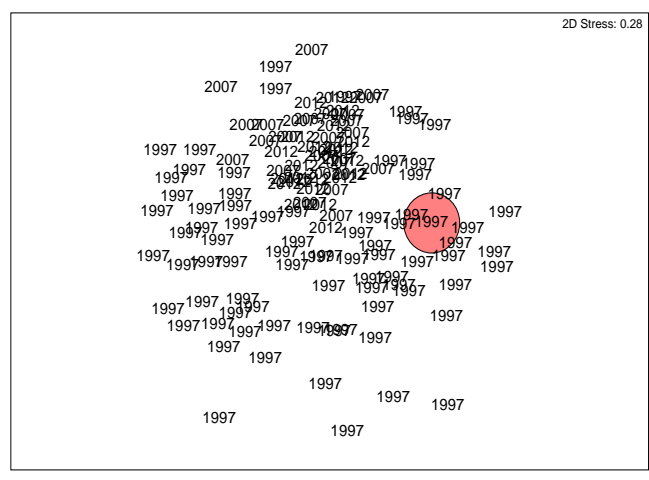

(a)

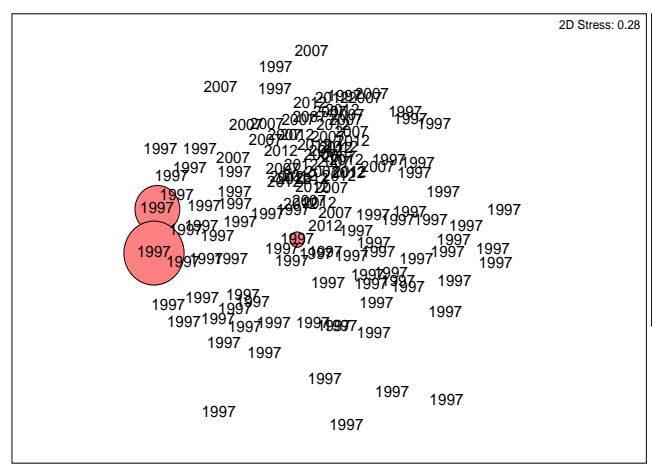

(c)
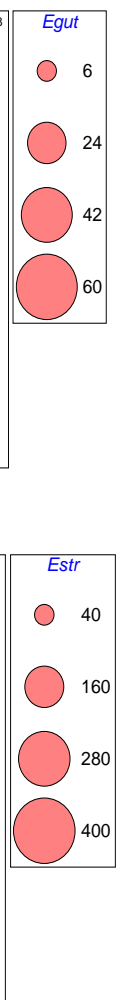

(1)

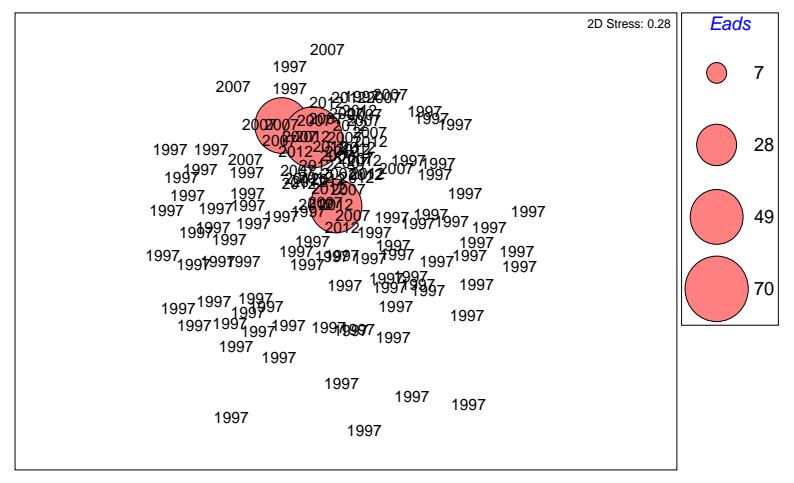

(b)

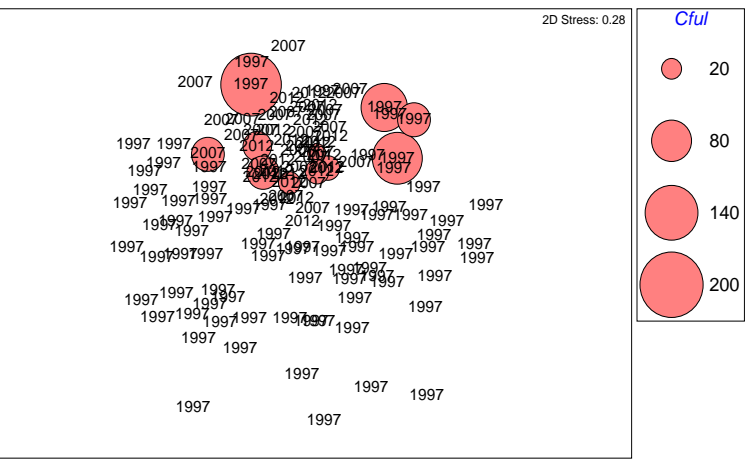

(d)

Figure 4. Bubble plots of spatio-temporal patterns of selected members of fishery-targeted sub-family Epinephelinae: (a) Epinephelus guttatus; (b) E. adscensionis; (c) E. striatus; and (d) Cephalopholis fulva. 
itajara), or deeper water grouper species of genus Mycteroperca were observed during the study. This pattern was very similar for representative members of snappers (Lutjanidae) (Figure 5). This included the Gray snapper (Lutjanus griseus), Schoolmaster (L. apodus), Mahogany snapper (L. mahogoni), and Yellowtail snapper (Ocyurus chrysurus). Although juveniles of Mutton snapper (L. analis) and Dog snapper (L. jocu) were sporadically observed across sites, no individuals were documented during visual censuses. Rapidly declining grouper and snapper populations coincided with increasing presence of invasive Lionfish (Pterois volitans), particularly during the 2012 fish counts. Lionfishes could have become a key mortality factor for juvenile fishes.

Important targeted members of parrotfishes (family Scaridae) also declined after 1997 across most sites (Figure 6). This included the Redtail parrotfish (Sparisoma chrysopterum), Stoplight parrotfish (Sp. viride), Queen parrotfish (Scarus vetula), and Blue parrotfish (Sc. coeruleus). No individuals of rare and highly overexploited species such as the Rainbow parrotfish (Sc. guacamaia) and the Midnight parrotfish (Sc. coelestinus) were observed during any of the surveys.

\subsection{Characterization of Stakeholder Groups}

Commercial fisherman relied on the reserve mainly on a seasonal basis and less so for key, commercial species such as Spiny lobster (Pannulirus argus), Queen conch (Lobatus gigas), and Yellowtail snapper (O. chrysurus). Also, fishermen did not exhibit any direct conflicts with other user groups. They also perceived a long-term decline in key, natural resource conditions in the reserve related to their livelihoods (i.e. commercial fisheries), and over $80 \%$ of them were generally in favor of a no-take MPA that exists on a de facto basis-ICA to LOB (and perhaps PLM) - due to the high volume of recreational use within and between those islands (Table 6). If a no-take MPA is to be implemented using stakeholder participation, the following should be considered: participation should involve open meetings that allow complete participation, over technical workshops and representative councils; fishermen's views on site location and allowable uses should be included in the information gathering and decision-making process; and, regardless of the governmental agency that would administer the no-take

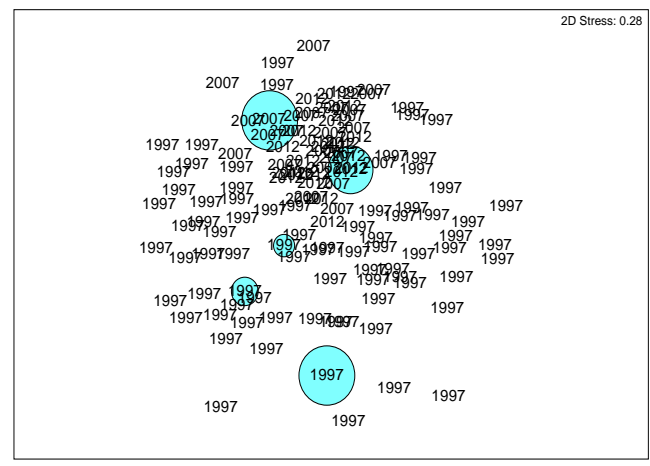

(a)

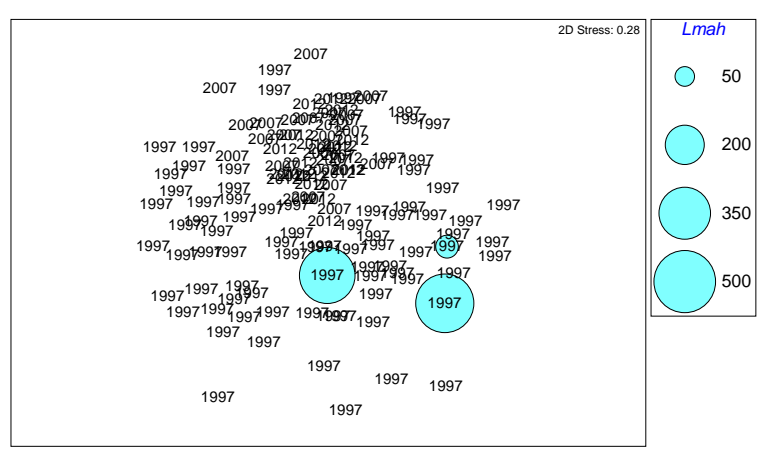

(c)
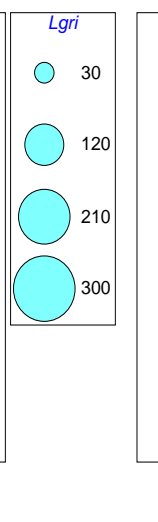

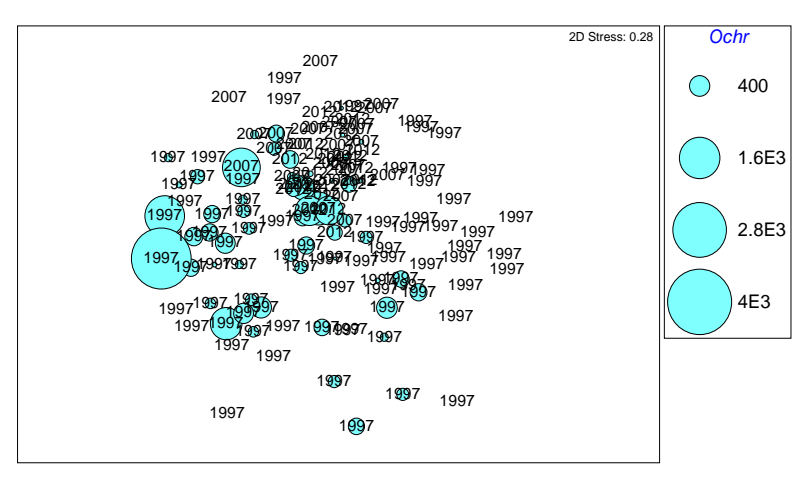

(d)

Figure 5. Bubble plots of spatio-temporal patterns of selected members of fishery-targeted family Lutjanidae: (a) Lutjanus griseus; (b) L. apodus; (c) L. mahogoni; and (d) Ocyurus chrysurus. 


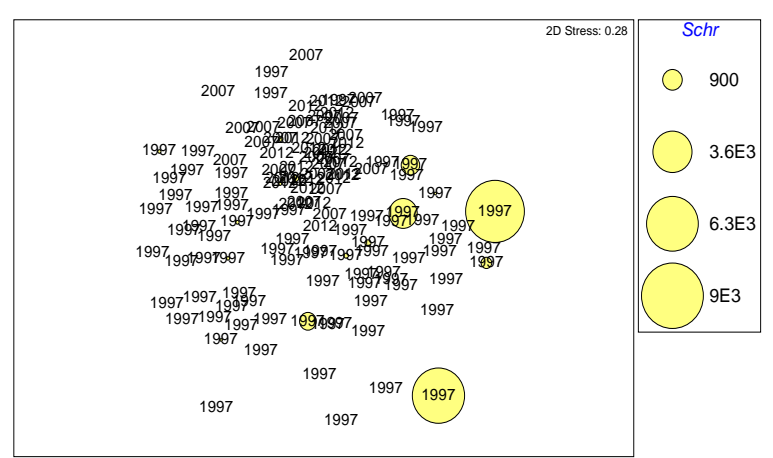

(a)

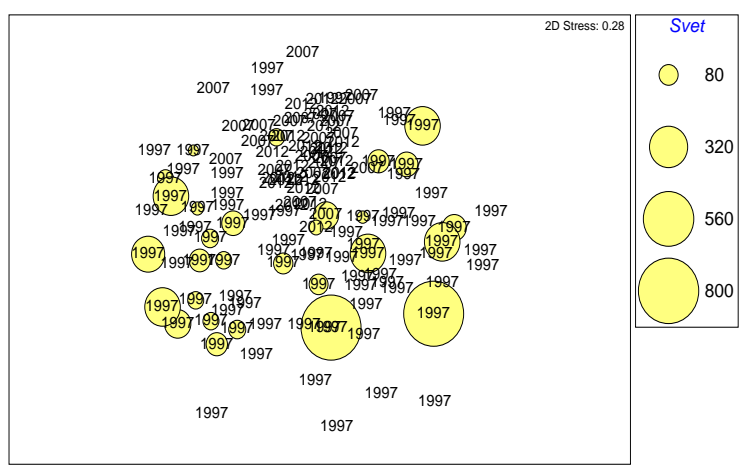

(c)

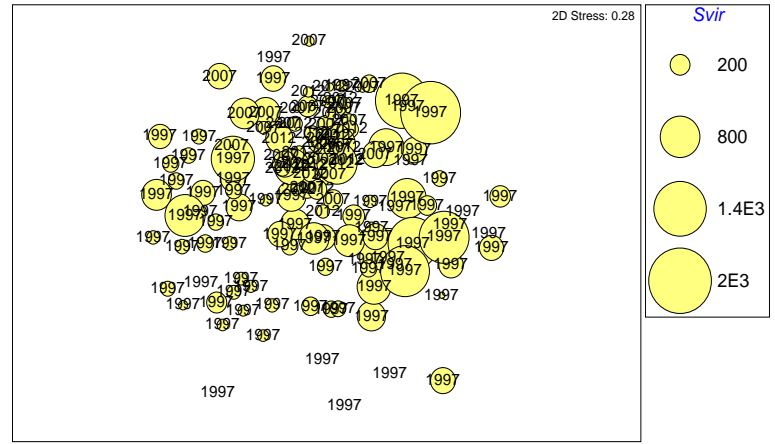

(b)

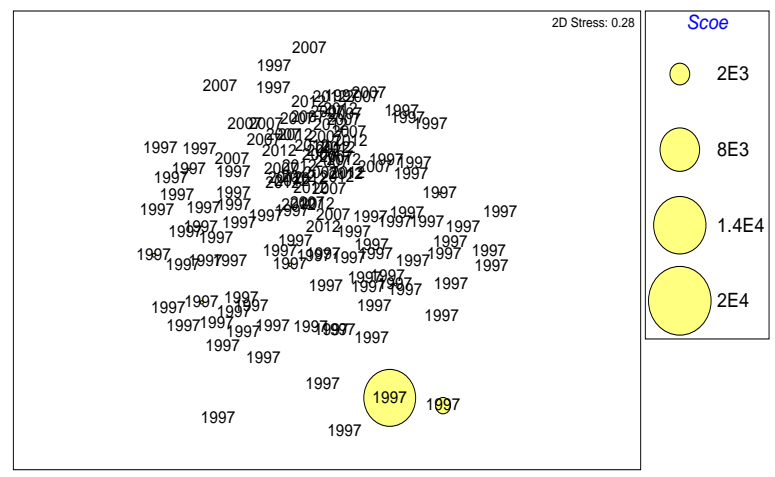

(d)

Figure 6. Bubble plots of spatio-temporal patterns of selected members of fishery-targeted family Scariidae: (a) Sparisoma chrysopterum; (b) Sp. viride; (c) Scarus vetula; and (d) Sc. coeruleus.

MPA, management should facilitate dialogue among the commercial fishing communities in the region and the PRDNER such that the former may improve trust in the agency.

Concessionaires were comprised of diverse interests, including dive and snorkel operators, catamaran and other large vessel operators, and fishing and other mixed-trip charters. The entire group relied extensively (in many cases, exclusively) on the reserve's coastal and marine resources for their livelihoods, and there was a majority view among respondents that the reserve's coral reef and related resources have declined over the past decade or longer. Most concessionaires also identified ICA and PLM as areas that experience high volumes of use and which are centers of use conflict, particularly from recreational divers and private recreational vessels. Due to these and other related factors (i.e., overfishing, water quality decline), over $70 \%$ of the concessionaires were in favor of a no-take MPA within the ALCNR (Table 7). The reserve, as would be designed by most respondents, would exclude commercial and recreational fishing but would allow non-consumptive uses, including diving, snorkeling, and cruising. The areas that were most often identified as candidate sites were those which were the waters around the most heavily visited islands, including ICA and LOB. Although less popular, concessionaires also identified DIA and PLM as islands around which to set up a no-take MPA. Concessionaires believed that reserve designation should involve mainly open meetings that allow the participation of all stakeholder groups and the public, while many concessionaires also favored having other forms of public participation, including technical workshops. Concessionaires were also more amenable than the commercial fishing group to have PRDNER manage the no-take MPA site, but most still preferred a US Federal Agency, mainly because of the latter's enforcement capability and financial capacity.

Registered vessel operators who visited the ALCNR were prolific boaters, taking five trips per month, each of which lasted over half a day (4.5 hours); thus, they represent a group that is most likely knowledgeable about the region and its resources, if not its designated status. That is, the results also demonstrated that while the operators took a majority, or almost $90 \%$, of their trips to the reserve, over a third of the respondents were unaware of the reserve or its boundaries. If the group were to be engaged in a process to set up a no-take MPA, part of the 
Table 7. Comparison of stakeholder characteristics and view towards no-take MPA designation and management.

\begin{tabular}{|c|c|c|c|c|c|c|c|c|}
\hline \multirow[b]{2}{*}{ Group } & \multicolumn{8}{|c|}{ Characteristics and views } \\
\hline & $\begin{array}{c}\text { Interactions with } \\
\text { MPA }\end{array}$ & $\begin{array}{l}\text { Reliance on } \\
\text { MPA }\end{array}$ & $\begin{array}{c}\text { Main activity on } \\
\text { MPA }\end{array}$ & $\begin{array}{l}\text { Views on } \\
\text { resource } \\
\text { conditions }\end{array}$ & $\begin{array}{c}\text { Views on } \\
\text { no-take MPA }\end{array}$ & $\begin{array}{l}\text { No-take } \\
\text { MPA } \\
\text { location }\end{array}$ & $\begin{array}{l}\text { Preferred } \\
\text { process }\end{array}$ & $\begin{array}{c}\text { Preferred } \\
\text { mgmt. } \\
\text { agency }\end{array}$ \\
\hline $\begin{array}{l}\text { Commercial } \\
\text { fishermen }\end{array}$ & $\begin{array}{l}\text { Consumptive, } \\
\text { extractive }\end{array}$ & $\begin{array}{l}\text { Moderate to } \\
\text { minimal }\end{array}$ & $\begin{array}{l}\text { Diving, line } \\
\text { fishing, some } \\
\text { trap fishing }\end{array}$ & Declining & $80 \%$ support & $\begin{array}{l}\text { Icacos, } \\
\text { Lobos }\end{array}$ & Meetings & Federal \\
\hline Dive charters & $\begin{array}{c}\text { Mostly } \\
\text { non-consumptive }\end{array}$ & High & $\begin{array}{l}\text { Diving off islands } \\
\text { and coral reefs }\end{array}$ & Declining & $73 \%$ support & $\begin{array}{l}\text { Icacos, } \\
\text { Diablo }\end{array}$ & $\begin{array}{l}\text { Meetings, } \\
\text { technical } \\
\text { workshops }\end{array}$ & Federal \\
\hline $\begin{array}{l}\text { Mixed trip } \\
\text { charters }\end{array}$ & $\begin{array}{c}\text { Mostly } \\
\text { non-consumptive }\end{array}$ & High & $\begin{array}{l}\text { Pleasure trips to } \\
\text { nearby islands }\end{array}$ & Declining & 73\% support & Icacos & $\begin{array}{l}\text { Meetings, } \\
\text { technical } \\
\text { workshops }\end{array}$ & Federal \\
\hline $\begin{array}{l}\text { Registered } \\
\text { vessel } \\
\text { operators }\end{array}$ & $\begin{array}{c}\text { Mixture of } \\
\text { consumptive and } \\
\text { non-consumptive }\end{array}$ & $\begin{array}{l}\text { Moderate to } \\
\text { high }\end{array}$ & $\begin{array}{l}\text { Pleasure trips to } \\
\text { nearby islands }\end{array}$ & N/A & $52 \%$ support & Icacos & $\begin{array}{l}\text { Need for } \\
\text { awareness, } \\
\text { education } \\
\text { within group }\end{array}$ & N/A \\
\hline
\end{tabular}

process would have to involve boater (and, indeed, general public) education on the existence of the reserve and its present boundaries and regulations. The results also determined that a smaller percentage of registered vessel operators (52\%), compared to the corresponding percentages of commercial fishermen (80\%) and concessionaires (73\%) supported a no-take MPA designation (Table 7). However, this lower support for a no-take MPA may have been a result of the methodology involved, which consisted of a formal, self-administered survey instrument that did not allow for respondents to select the types of uses that could be restricted and choices between designation processes and different management agencies. Notwithstanding those constraints, over $90 \%$ of those who did identify a recommended no-take MPA in the reserve selected ICA, which was more popular than the adjacent LOB and PLM, but which together garnered support for closure from over $70 \%$ of the registered vessel operators.

\subsection{Geospatial Rankings of Candidate No-Take MPA Sites}

Table 8 summarized the multi-criteria ranking analysis of candidate no-take zones within ALCNR. Overall, SDP ranked as the most significant site for a no-take MPA designation, with an 83\% combined score. It was followed by DIA with a score of 75\%, and PLM and LOB, with 74\%, each one. PLT followed with 70\%, ICAW with $65 \%$. ICAE scored $47 \%$. These results suggest that based on a combination of criteria, three different complexes emerged as potential candidate no-take zones: SDP-DIA, PLM-PLT, and ICAE-ICAW-LOB. SDP-DIA ranked highest under most criteria, but particularly under biological criteria. These sites were located at approximately $10 \mathrm{~km}$ off the Fajardo coast and showed the lowest density of visitors and the most diverse and abundant fish assemblages. Distance and strong oceanographic conditions is a major constraint largely reducing recreational activities east of LOB towards DIA. Nonetheless, these are the sites with potentially stronger conflicts with commercial fishermen. PLM-PLT is an area that also showed a moderately high ranking by a combination of criteria. Most stakeholders supported its designation as a no-take zone due to several reasons, including proximity to marinas and hotels at the eastern coast of PR $(<6 \mathrm{~km})$, easy access, usually protected conditions at frequented areas, and because of its overfished state. Similar justifications were presented for supporting the designation of the ICAE-ICAW-LOB complex.

There was a strong agreement between stakeholder perceptions of the status of ALCNR's natural resources (i.e., fish communities, benthic communities, water quality, cleanliness, etc.) and empirical data obtained in this study regarding the status of fish communities within the reserve that strongly support the immediate designation of no-take zones. After careful consideration of empirical evidence regarding the depauperate condition of fish communities within ALCNR with increasing time in comparison to the 1997 baseline, we strongly recommend the designation of three zones as no-take MPAs as a consensus option (Figure 7): 1) ICAE-ICAW-LOB complex, 2) PLM-PLT island complex, and 3) SDP-DIA. This alternative will protect significant essential fish habitats, will facilitate compliance and enforcement of no-take zones as units can be easily identified and demarcated with buoys. This alternative adjusts better to a consensus model more compatible with the options supported by fishermen and other user groups, while simultaneously protecting overexploited resources by overfishing and by recreational activities, as well as protecting critical areas that still support healthy fish populations. 
Table 8. Multi-criteria ranking analysis of candidate no-take MPA sites.

\begin{tabular}{|c|c|c|c|c|c|c|c|}
\hline Criteria & DIA & PLM & PLT & SDP & LOB & ICAE & ICAW \\
\hline \multicolumn{8}{|l|}{ Biological } \\
\hline Species richness & 1 & 1 & 1 & 2 & 1 & 0 & 1 \\
\hline Species diversity index (H’n) & 1 & 1 & 1 & 2 & 2 & 0 & 2 \\
\hline Evenness (J’n) & 1 & 1 & 2 & 1 & 2 & 0 & 2 \\
\hline Total abundance & 1 & 1 & 1 & 2 & 1 & 0 & 1 \\
\hline Total herbivores & 1 & 1 & 1 & 2 & 1 & 0 & 2 \\
\hline Non-denuders & 1 & 2 & 1 & 0 & 1 & 0 & 1 \\
\hline Browsers & 1 & 0 & 1 & 2 & 1 & 1 & 1 \\
\hline Scrapers & 1 & 2 & 1 & 2 & 1 & 0 & 2 \\
\hline Omnivores & 0 & 0 & 2 & 2 & 1 & 0 & 0 \\
\hline Total carnivores & 2 & 1 & 0 & 2 & 1 & 0 & 0 \\
\hline Generalists & 2 & 1 & 0 & 1 & 1 & 1 & 1 \\
\hline Planktivores & 2 & 1 & 2 & 2 & 1 & 0 & 0 \\
\hline Piscivores & 0 & 2 & 0 & 1 & 0 & 0 & 0 \\
\hline Fishery target species & 1 & 2 & 1 & 2 & 1 & 0 & 1 \\
\hline Total biomass & 1 & 1 & 0 & 2 & 1 & 0 & 1 \\
\hline Total herbivores & 1 & 1 & 1 & 2 & 1 & 0 & 1 \\
\hline Non-denuders & 1 & 2 & 0 & 2 & 1 & 2 & 1 \\
\hline Browsers & 0 & 0 & 1 & 2 & 1 & 0 & 1 \\
\hline Scrapers & 1 & 1 & 0 & 2 & 1 & 0 & 1 \\
\hline Omnivores & 2 & 1 & 1 & 1 & 1 & 0 & 1 \\
\hline Total carnivores & 1 & 1 & 0 & 2 & 1 & 0 & 0 \\
\hline Generalists & 1 & 1 & 0 & 2 & 1 & 0 & 0 \\
\hline Planktivores & 1 & 0 & 2 & 1 & 1 & 0 & 0 \\
\hline Piscivores & 1 & 1 & 1 & 2 & 1 & 0 & 0 \\
\hline Fishery target species & 2 & 1 & 2 & 1 & 1 & 0 & 1 \\
\hline Reef structural heterogeneity index & 1 & 1 & 0 & 2 & 1 & 0 & 0 \\
\hline Points $(\max =52)$ & 28 & 27 & 22 & 44 & 27 & 4 & 21 \\
\hline Sub-score & 53.8 & 51.9 & 42.3 & 84.6 & 51.9 & 7.7 & 40.4 \\
\hline \multicolumn{8}{|l|}{ Ecological } \\
\hline Biodiversity & 2 & 2 & 2 & 2 & 2 & 1 & 2 \\
\hline Naturalness & 1 & 1 & 1 & 2 & 1 & 0 & 1 \\
\hline Dependency & 2 & 2 & 2 & 2 & 2 & 2 & 2 \\
\hline Representativeness & 2 & 2 & 2 & 2 & 2 & 1 & 2 \\
\hline Uniqueness & 2 & 1 & 2 & 1 & 2 & 1 & 1 \\
\hline Integrity & 2 & 2 & 2 & 2 & 2 & 1 & 1 \\
\hline Productivity & 1 & 2 & 1 & 2 & 0 & 0 & 0 \\
\hline Ecological status benthic communities & 1 & 0 & 1 & 1 & 0 & 0 & 0 \\
\hline Connectivity to other reefs & 2 & 2 & 2 & 2 & 2 & 2 & 2 \\
\hline Points $(\max =18)$ & 15 & 14 & 15 & 16 & 13 & 8 & 11 \\
\hline Sub-score & 83.3 & 77.8 & 83.3 & 88.9 & 72.2 & 44.4 & 61.1 \\
\hline
\end{tabular}




\section{Continued}

Regional

Regional significance

Subregional significance

Subregional connectivity

Points $(\max =6)$

Sub-score

100

2
2
2
6

Impacts

Vulnerability

$\begin{array}{lllllll}100 & 100 & 100 & 100 & 100 & 50 & 83.3\end{array}$

Degree of threat

Evident overfishing effects

Points $(\mathbf{n}=6)$

Sub-score

2
2
2
6

Pragmatic

$\begin{array}{lllllll}100 & 100 & 100 & 83.3 & 100 & 100 & 100\end{array}$

Urgency

Size

Effectiveness

Opportunism

Availability

Restorability

Points $(\max =12)$

2

Sub-score

2
2
2
2
2
2

Economic

Importance to species

Importance to fisheries

Nature of threats

Economic benefits

Tourism

Points $(\max =10)$

$\begin{array}{rrrrrrr}12 & 11 & 11 & 11 & 12 & 10 & 11\end{array}$

Sub-score

$\begin{array}{ccccccc}2 & 2 & 2 & 2 & 1 & 1 & 1 \\ 1 & 1 & 1 & 2 & 1 & 1 & 1 \\ 2 & 2 & 2 & 2 & 2 & 2 & 2 \\ 2 & 2 & 2 & 2 & 2 & 2 & 2 \\ 2 & 2 & 2 & 2 & 2 & 2 & 2 \\ \mathbf{9} & \mathbf{9} & \mathbf{9} & \mathbf{1 0} & \mathbf{8} & \mathbf{8} & \mathbf{8} \\ \mathbf{9 0} & \mathbf{9 0} & \mathbf{9 0} & \mathbf{1 0 0} & \mathbf{8 0} & \mathbf{8 0} & \mathbf{8 0}\end{array}$

Social

Social acceptance

Recreation

Culture

Aesthetics

Conflicts of interest

Safety

Accessibility

Research and education

Public awareness

Conflict and compatibility

Benchmark

Points $(\max =22)$

\begin{tabular}{|l|l|}
\hline 1 \\
\hline 2 \\
\hline 2 \\
\hline 1 \\
1 \\
\hline 2 \\
2 \\
2 \\
2 \\
2
\end{tabular}

Sub-score

\begin{tabular}{ccccccc}
\hline 1 & 2 & 2 & 1 & 2 & 2 & 2 \\
\hline 2 & 2 & 2 & 0 & 2 & 2 & 2 \\
1 & 2 & 1 & 2 & 2 & 2 & 2 \\
2 & 2 & 2 & 1 & 2 & 2 & 2 \\
1 & 2 & 2 & 0 & 2 & 2 & 2 \\
1 & 1 & 1 & 0 & 2 & 2 & 2 \\
2 & 2 & 2 & 2 & 2 & 2 & 2 \\
2 & 2 & 2 & 2 & 2 & 2 & 2 \\
2 & 2 & 2 & 1 & 2 & 2 & 2 \\
2 & 2 & 2 & 2 & 2 & 2 & 2 \\
2 & 1 & 1 & 2 & 1 & 1 & 1 \\
\hline 18 & $\mathbf{2 0}$ & $\mathbf{1 9}$ & $\mathbf{1 3}$ & $\mathbf{2 1}$ & $\mathbf{2 1}$ & $\mathbf{2 1}$ \\
$\mathbf{8 2}$ & $\mathbf{9 1}$ & $\mathbf{8 6}$ & $\mathbf{5 9}$ & $\mathbf{9 5}$ & $\mathbf{9 5}$ & $\mathbf{9 5}$ \\
\hline $\mathbf{9 4}$ & $\mathbf{9 3}$ & $\mathbf{8 8}$ & $\mathbf{1 0 5}$ & $\mathbf{9 3}$ & $\mathbf{5 9}$ & $\mathbf{8 2}$ \\
$\mathbf{7 5}$ & $\mathbf{7 4}$ & $\mathbf{7 0}$ & $\mathbf{8 3}$ & $\mathbf{7 4}$ & $\mathbf{4 7}$ & $\mathbf{6 5}$ \\
\hline
\end{tabular}

Cumulative points $(\max =126)$

Final score

Rank scores: 0 = Low ranking; 1 = Moderate ranking; 2 = High ranking. Total maximum score was 22 cumulative points. 


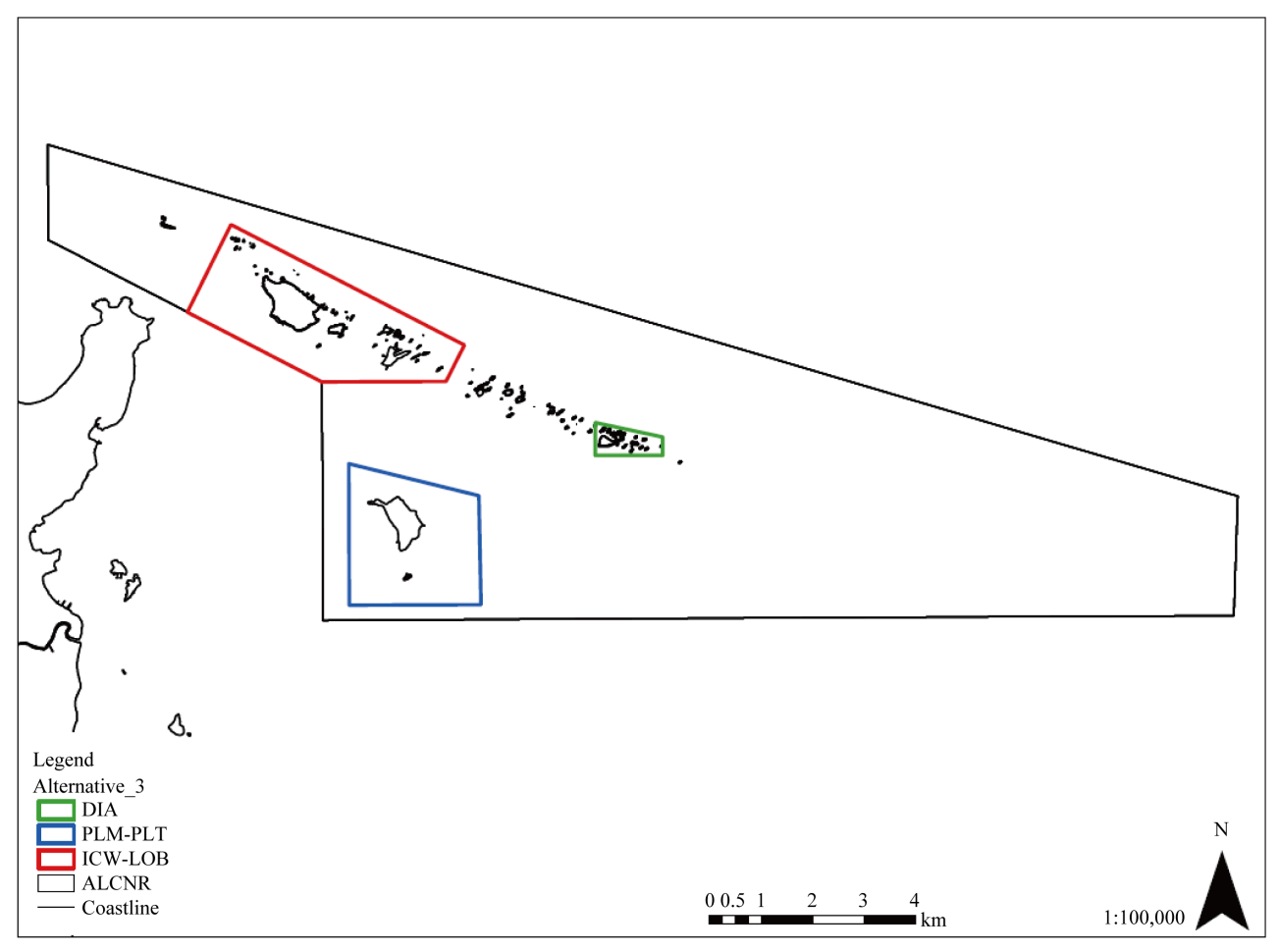

Figure 7. Recommended no-take zone network designation. Red polygon (ICAE, ICAW, LOB); Blue polygon (PLM, PLT); Green polygon (DIA).

At the same time it also maintains important areas subjected to very strong ocean circulation between SDP and LOB open to artisanal fishing to protect the traditional livelihoods of local fishing communities. Respecting traditional uses within these communities is a critical element necessary to build trust with local stakeholders, and develop and compliance within any no-take MPA. The proposed network design will help improve connectivity among proposed no-take zones and will improve fish spillover effects to adjacent areas open to fishing.

\section{Discussion}

\subsection{Ecosystem-Based Model Output}

Since its designation in 1980, recreational and commercial fishing activities across ALCNR have been poorly managed. Populations of the most significant fishery-targeted species were significantly depleted, apex predators were largely absent from most reefs, particularly during the 2007 and 2012 surveys. The most significant predators were small or medium-sized commercial predators, and herbivore guilds were dominant across most sites. Several fish functional groups were largely depleted through most of the study sites, particularly in areas subjected to very intense recreational activities, including non-regulated spearfishing. Piscivore guilds were the most affected. Most grouper (Serranidae), snapper (Lutjanidae), and barracuda (Sphyraenidae) populations were significantly depleted or completely absent at most sites. This pattern was evident also for some grunts (Haemulidae) and parrotfishes (Scaridae). Further, most individuals of fishery-targeted species observed belonged to smaller size categories. Other significant fishery-targeted groups such as triggerfishes (Balistidae), porcupinefish (Diodontidae), highly-prized species such as Nassau Grouper (Epinephelus striatus), or entire genera such as Mycteroperca spp. were totally absent during the entire study. Such trends suggest an unequivocal long-term impact of fishing of apex predators and of heavy exploitation of primarily carnivorous trophic level fishes similar to those observed elsewhere [2] [34]-[37]. Fishing impacts can also have significant indirect effects on benthic community structure [9] [38] [39]. The actual status of coral reef fish communities within ALCNR is a major cause of concern that requires rapid action to significantly reduce or eliminate consumptive uses through the establishment of a network of small, discrete no-take MPAs, with strong community-based participation and support through a co-management model. 


\subsection{The Ticking Clock of Climate Change: Impacts on Reef Fisheries}

Climate change has also become a critical driver of coral reef decline. The northeastern Caribbean region underwent two significant sea surface warming episodes in 1998 and 2005 that resulted in massive coral bleaching and post-bleaching mass coral mortality events with paramount negative impacts on coral reefs [40]-[44]. Declining habitat conditions have resulted in altered fish community structure [11]-[14]. Climate change and exploitation can significantly interact in their effects, such that climate may cause failure in a fishery management scheme [45], particularly under weak governance conditions and limited enforcement scenarios. Fishery exploitation may also disrupt the ability of a resource population to withstand, or adjust to, climate changes. Therefore, climate-related habitat decline and exploitation could result in altered demography, parental effects, altered migration or declining connectivity of important species [45]. At the ecosystem level, reduced complexity by elimination of species (i.e., fishing), may be destabilizing, and it may result in declining functional redundancy [46], and could lead to reduced resilience to disturbance [47]. Differential exploitation of marine resources and climate change could also promote increased turnover rates in marine ecosystems [48], which would exacerbate the effects of environmental changes. Declining coral reef biodiversity will also likely lead to a reduction in the resilience and to an increase in the response of populations and ecosystems to future climate variability and change [45]. If detrimental human impacts to coral reefs are reduced and key ecological processes are enhanced, pulse disturbances and ecological variability may provide opportunities for returning to a coral-dominated state, which could enhance ecosystem resilience, benefits and services [49]. Future management strategies will have to consider the structure and functioning of populations and ecosystems in a wider sense in order to maximize their ability to respond to changing climate and significantly improve their resilience. In that sense, no-take MPAs can become critical tools to restore and conserve populations and ecosystems structure and functioning.

\subsection{Community-Based Participatory Model Output}

All stakeholder groups agreed that coral reef conditions in the reserve had declined, as had associated resources such as water quality which has affected the health of the coral reefs and fisheries which depended on healthy coral reefs. While the stakeholder groups believed that there were a myriad of causes for the decline, there was general consensus that overfishing (resulting from commercial and recreational fishing) and land-based source pollution (especially as related to coastal and marine tourism, sedimentation, and water quality) had been responsible. Importantly, stakeholders did not recognized climate change and sea surface warming as threats to coral reefs and fisheries which raises a major concern regarding the lack of a public educational and outreach program regarding the consequences and impacts of climate change. The stakeholders mostly accepted the solution of implementing a no-take MPA and may actually have been addressing their concerns over resource decline by identifying the most heavily used areas (the ICA-LOB-PLM complex) as those which deserve the highest protection. While it is clear that non-consumptive stakeholder groups stand to gain the most by restricting access to all other kinds of uses within a no-take MPA, the study revealed that even consumptive groups such as commercial fishermen, fishing charters, and consumptive dive charters generally did not oppose the implementation of a no-take MPA. Their perceptions were consistent with dive tourist perceptions in Belize which suggested that adequate enforcement of no-take MPAs should improve coral reef conditions [50]. All groups agreed that a no-take MPA will help recover depleted fisheries, but did not recognize the value of no-take MPAs as a tool to potentially buffer against climate change-related impacts by maintaining higher coral reef ecosystem resilience.

As important as reaching consensus on the location and characteristics of a no-take MPA was the determination of the process to be used to foster public participation in a format that stakeholders considered would be fair and equitable and the identification of the management agency which stakeholders believed would be best positioned to ensure enforcement and management efficacy. While not discussed in any detail in this study, it was found via commercial fishermen and concessionaire interviews that the stakeholder groups held a dim view on public participation; that is, members of both groups often felt that meetings addressing resource management issues were often poorly advertised and held at hours when they could not attend. Others believed that public participation, while allowed and even promoted, made little difference in influencing the final decisions. However, stakeholders still preferred holding meetings as part of the decision-making process for a no-take MPA instead of other formats, such as technical workshops or representative councils. In terms of identifying the agency that could best implement a no-take MPA, most stakeholders were in favor of a US Federal Agency, particu- 
larly the US Fish and Wildlife Service (USFWS). It is likely that the USFWS was most commonly cited because it is the primary federal, natural resource agency that most stakeholders are aware of in the region, through experiences with the Vieques National Wildlife Refuge and the Culebra National Wildlife Refuge. Thus, at the federal level at least, stakeholders are not fully aware of other models, including national parks and, in particular, national marine sanctuaries, which have never been implemented in PR.

Also, there remains the need to better understand and ameliorate the mainly negative views that many stakeholders, and especially commercial fishermen, hold towards the local government enforcement agency, PRDNER. Many stakeholders interviewed as part of the study believed that the local government did not have the financial or enforcement capacity to manage a no-take MPA. Others felt that the agency was draconian and thus did not foster stakeholder confidence in being fair in the management of a no-take MPA. Finally, a few respondents perceived the government as having failed to adequately protect the regional natural reserves, including Canal Luis Peña No-take Natural Reserve, in Culebra Island, and ALCNR, and argued that the enforcement agency could not handle additional management tasks. These examples are raised here to highlight the pervasive views held by many stakeholders concerning the government and to recommend that any no-take MPA designation process consider improving stakeholder understanding of agency's missions and objectives, its management actions and accomplishments, and an overall rehabilitation of the agency's image in relation to stakeholder trust.

\subsection{Ecosystem-Based and Community-Based Model Integration}

Information from ecosystem-based and community-based participatory models was successfully merged to create a multi-criteria data matrix to evaluate and rank candidate no-take MPAs. MPA designation typically relies in scientific information (i.e., oceanographic, biological, ecological), but rarely in societal, which might explain why so many MPAs may fail to meet their objectives [15]. Because the placement, design, and management of no-take MPAs are all related to the intended goals, the most crucial information is that related to the specific objectives the MPA is designed to achieve which is essentially societal [51]. Literature concerning the human dimensions of no-take MPAs has demonstrated both the need to consider human uses in MPA management processes [33] [52]-[54], and to incorporate public participation at the various stages of the MPA cycle, from designation [55] [56], to reassessment and monitoring [57]-[59]. Uses and concerns, when left unidentified, can undermine the effectiveness of no-take MPAs, manifested as incomplete characterizations of socioeconomic uses [55], inter-group conflicts [56]-[61], and mistrust of management intentions or processes [62] [63]. Conversely, when human dimensions are integrated into the decision-making process in no-take MPA designation stage and throughout the management process, MPAs often perform to their expectations rather than being relegated as "paper parks". Successful no-take MPA designation approaches, such as that used for the designation of the Dry Tortugas Ecological Reserve in the Florida Keys National Marine Sanctuary [64], are those that accept stakeholder knowledge, acknowledge stakeholder concerns, and engage stakeholder participation in a transparent and consensus-building process. A combination of base community support, management measures and enforcement of regulations contributed towards positive ecological trends in MPAs [65]. Societal integration and participation has also been identified as key elements for successful implementation of ecosystem-based management of MPAs [66] and for climate change adaptation [67]. MPAs often attract increased numbers of tourists, often resulting in increased water-based visitation and impacts [68]. Ecosystem-based and community-based participatory model integration will allow for reaching consensus regarding the identification of key problems, potential solutions to diminish such impacts, and for the implementation of management strategies.

\section{Conclusions}

This study addressed the spatio-temporal changes in fish community structure at ALCNR within a 15-year time span (1997-2012), identified areas of convergence between different stakeholder groups, ranked candidate no-take MPA sites based in multiple criteria, evaluated the preferred methods of public participation within and between community groups, and determined community expectations of no-take MPA benefits and costs. Information gathered contributed to devising and prioritizing strategies by which to maximize coral reef-associated fisheries protection while enabling public participation and maximizing community support for no-take MPAs. No-take MPA implementation linked to habitat protection and management can be an important tool to recover already depleted fish populations and significantly depleted coral reefs within ALCNR that have also been impacted by climate change. We strongly recommend the designation of three areas within the reserve as 
no-take zones, based on a consensus model more compatible with the options supported by fishermen and other user groups, which can simultaneously protect overexploited resources from fishing and by a myriad of recreational activities. We particularly recommend protecting critical areas that still support healthier fish populations, and at the same time protecting local fishermen's livelihoods by maintaining their principal fishing grounds open to fishing.

A final recommendation is that there remain several critical research needs. The first is to understand the coral reef ecosystem configurations possible under different future scenarios of stress levels, habitat types and biogeographic location [69]. There is also a need to understand how ecosystem processes will be influenced by changing environmental conditions and species compositions, particularly in the context of typical non-sustainable coastal and tourism development practices in tropical islands [70] which results in significant sediment loads to coral reefs [71]-[74]. Finally, there is a need to assess which management approaches will be most appropriate for novel coral reef future scenarios with potentially reduced species diversity, minimal living coral cover, lower functional redundancy, and compromised resilience. There would be a need to reassess the effects the effects and appropriateness of current management approaches, and trialing innovative management options that manage exploited but functional systems [69]. Such approaches include ecosystem-based and community-based participatory model integration.

The approach used in this study conferred a series of benefits and advantages, including: 1) a relatively open-ended interviews allowing for a broad discussion on MPA management strategies; 2) important baseline biological data and stakeholder and interest group participation in the development of management strategies for the MPA; 3) baseline information useful to develop an ecosystem-based long-term ecological monitoring program; 4) a study that targeted at specific user groups with a variety of views, including those of consumptive and non-consumptive stakeholder groups, special interest and public interest groups, and others; 5) an approach that incorporated both qualitative and quantitative aspects of social science in that it used multiple tools such as semi-structured interviews, focus group sessions, as well as participatory surveys, to complete a comprehensive characterization of community and visitor views on an MPA; and 6) a study that relied on inputs at various levels and disciplines; the amount of information collected was maximized, and results are applicable to similar areas through the Caribbean. In the context of rapid climate change impacts and increasing exploitation of fishery resources, the integration of ecosystem-based and community-based models fostering strong stakeholder participation has become an important strategy to restore depleted resources and rehabilitate coral reef ecosystem resilience, functions and benefits. Coral reefs have changed in unprecedented ways. There is a need to explore new management approaches, assess changes in ecosystem services, and investigate how human societies can adapt and respond to novel futures [69]. Ecosystem-based and community-based model integration may be critical to foster long-term community-based integration to develop and implement mitigation strategies for climate change impacts, as well as to improve governance. Failing to take action now may compromise important reef resources in the near future.

\section{Acknowledgements}

This study was made possible thanks to the support provided by NOAA's Coral Reef Conservation Program (NA05NMF4631050). Support was also provided to E.A.H.D. by the Caribbean Coral Reefs Institute of the University of Puerto Rico (UPR) (NA04NOS4260206), and by the National Science Foundation through the Center for Applied Tropical Ecology and Conservation of UPR (HRD \#0734826). Our appreciation to Robert Matos (Former Director, Reserves and Refuges Bureau, PRDNER) and Héctor Horta (Former Officer Manager, ALCNR, PRDNER) for logistical support during some phases of the project.

\section{References}

[1] Roberts, C.M. and Polunin, N.V.C. (1993) Marine Reserves: Simple Solutions to Managing Complex Fisheries? AMBIO, 22, 363-368.

[2] Roberts, C.M. (1995) Rapid Build-Up of Fish Biomass in a Caribbean Marine Reserve. Conservation Biology, 9, 815826. http://dx.doi.org/10.1046/j.1523-1739.1995.09040815.x

[3] Bohnsack, J.A. (1998) Application of Marine Reserves to Reef Fisheries Management. Australian Journal of Ecology, 23, 298-304. http://dx.doi.org/10.1111/j.1442-9993.1998.tb00734.x

[4] Roberts, C.M., Bohnsack, J.A., Gell, F., Hawkins, J.P. and Goodridge, R. (2001) Effects of Marine Reserves on Adja- 
cent Fisheries. Science, 294, 1920-1923. http://dx.doi.org/10.1126/science.294.5548.1920

[5] Roberts, C.M., Branch, G., Bustamante, R.H., Castilla, J.C., Dugan, J., Halpern, B.S., Lafferty, K.D., Leslie, H., Lubchenco, J., McArdle, D., Ruckelshaus, M. and Warner, R.R. (2003) Application of Ecological Criteria in Selecting Marine Reserves and Developing Reserve Networks. Ecological Applications, 13, S215-S228.

http://dx.doi.org/10.1890/1051-0761(2003)013[0215:AOECIS]2.0.CO;2

[6] McClanahan, T.R., Marmane, M.J., Cinner, J.E. and Kiene, W.E. (2006) A Comparison of Marine Protected Areas and Alternative Approaches to Coral-Reef Management. Current Biology, 16, 1408-1413.

[7] Stobart, B., Warwick, R., González, C., Mallol, S., Díaz, D., Reñones, O. and Goñi, R. (2009) Long-Term and Spillover Effects of a Marine Protected Area on an Exploited Fish Community. Marine Ecology Progress Series, 384, 47-60. http://dx.doi.org/10.3354/meps08007

[8] Burke, L. and Maidens, J. (2004) Reefs at Risk in the Caribbean. WRI, Washington DC.

[9] Hawkins, J.P. and Roberts, C.M. (2004) Effects of Artisanal Fishing on Caribbean Coral Reefs. Conservation Biology, 18, 215-226. http://dx.doi.org/10.1111/j.1523-1739.2004.00328.x

[10] Paddack, M.J., Reynolds, J.D., Aguilar, C., Appeldoorn, R.S., Beets, J., Burkett, E.W., Chittaro, P.M., Clarke, K., Esteves, R., Fonseca, A.C., Forrester, G.E., Friedlander, A.M., García-Sais, J., González-Sansón, G., Jordan, L.K.B., McClellan, D.B., Miller, M.W., Molloy, P.P., Mumby, P.J., Nagelkerken, I., Nemeth, M., Navas-Camacho, R., Pitt, J., Polunin, N.V.C., Reyes-Nivia, M.C., Robertson, D.R., Rodríguez-Ramírez, A., Salas, E., Williams, I.D., Wormald, C.L., Watkinson, A.R. and Côté, I.M. (2009) Recent Region-Wide Declines in Caribbean Reef Fish Abundance. Current Biology, 19, 1-6. http://dx.doi.org/10.1016/j.cub.2009.02.041

[11] Jones, G.P., McCormick, M.I., Srinivasan, M., Eagle, J.V. and Paine, R.T. (2004) Coral Decline Threatens Fish Biodiversity in Marine Reserves. Proceedings of the National Academy of Sciences of the United States of America, 101, 8251-8253. http://dx.doi.org/10.1073/pnas.0401277101

[12] Pratchett, M.S., Munday, P.L., Wilson, S.K., Graham, N.A.J., Cinner, J.E., Bellwood, D.R., Jones, G.P., Polunin, N.V.C. and McClanahan, T.R. (2008) Effects of Climate-Induced Coral Bleaching on Coral-Reef Fishes-Ecological and Economic Consequences. Oceanography and Marine Biology: An Annual Review, 46, 251-296. http://dx.doi.org/10.1201/9781420065756.ch6

[13] Pratchett, M.S., Hoey, A.S. and Wilson, S.K. (2014) Reef Degradation and the Loss of Critical Ecosystem Goods and Services Provided by Coral Reef Fishes. Current Opinion in Environmental Sustainability, 7, 37-43. http://dx.doi.org/10.1016/j.cosust.2013.11.022

[14] Selig, E.R., Casey, K.S. and Bruno, J.F. (2012) Temperature-Driven Coral Decline: The Role of Marine Protected Areas. Global Change Biology, 18, 1561-1570. http://dx.doi.org/10.1111/j.1365-2486.2012.02658.x

[15] Appeldoorn, R.S. and Lindeman, K.C. (2003) A Caribbean-Wide Survey of Marine Reserves: Spatial Coverage and Attributes of Effectiveness. Gulf and Caribbean Research, 14, 139-154.

[16] Aguilar-Perera, A., Schärer, M. and Valdés-Pizzini, M. (2006) Marine Protected Areas in Puerto Rico: Historical and Current Perspectives. Ocean and Coastal Management, 49, 961-975. http://dx.doi.org/10.1016/j.ocecoaman.2006.08.011

[17] Montilla-Despiau, I. (2012) Evaluación Rápida del Arrecife de Isla Verde e Impactos Ambientales Presentes. M.Sc. Thesis, Environmental Affairs Graduate School, Universidad Metropolitana, San Juan, 1-132.

[18] Matos-Caraballo, D. (2009) Lessons Learned from the Puerto Rico’s Commercial Fishery, 1988-2008. Proceedings of the Gulf and Caribbean Fisheries Institute, 61, 123-129.

[19] Hernández-Delgado, E.A. and Sabat, A.M. (2000) Ecological Status of Essential Fish Habitats through an Anthropogenic Environmental Stress Gradient in Puerto Rican Coral Reefs. Proceedings of the Gulf and Caribbean Fisheries Institute, 51, 457-470.

[20] Bejarano-Rodríguez, I. (2006) Relationships between Reef Fish Communities, Water and Habitat Quality on Coral Reefs. M.Sc. Thesis, University of Puerto Rico, Mayagüez, 51.

[21] Hernández-Delgado, E.A. (2000) Effects of Anthropogenic Stress Gradients in the Structure of Coral Reef Epibenthic and Fish Communities. Ph.D. Dissertation, University of Puerto Rico, San Juan, 330.

[22] Alcala, A.C., Bucol, A.A. and Nillos-Kleiven, P. (2008) Directory of MarineReserves in the Visayas, Philippines. Foundation for the Philippine Environment and Silliman University-Angelo King Center for Research and Environmental Management (SUAKCREM), Dumaguete City, 1-178.

[23] Bohnsack, J.A. and Bannerot, S.P. (1986) A Stationary Visual Census Technique for Quantitatively Assessing Community Structure of Coral Reef Fishes. NOAA Technical Report NMFS, 41, 1-15.

[24] Shannon, C.E. and Weaver, W. (1948) The Mathematical Theory of Communication. University of Illinois Press, Urbana, 1-117. 
[25] Pielou, E.C. (1966) The Measurement of Diversity in Different Types of Biological Collections. Journal of Theoretical Biology, 13, 131-144. http://dx.doi.org/10.1016/0022-5193(66)90013-0

[26] Clarke, K.R. and Warwick, R.M. (2001) Change in Marine Communities: An Approach to Statistical Analysis and Interpretation. 2nd Edition, PRIMER-E, Ltd., Plymouth Marine Laboratory, Plymouth.

[27] Anderson, M.J., Gorley, R.N. and Clarke, K.R. (2008) PERMANOVA for PRIMER: Guide to Software and Statistical Methods. PRIMER-E, Plymouth.

[28] Bray, J.R. and Curtis, J.T. (1957) An Ordination of the Upland Forest Communities of Southern Wisconsin. Ecological Monographs, 27, 325-349. http://dx.doi.org/10.2307/1942268

[29] Agar, J.J., Waters, J.R., Valdés-Pizzini, M., Shivlani, M., Murray, T., Kirkley, J.E. and Suman, D. (2008) US Caribbean Fish Trap Fishery Socioeconomic Study. Bulletin of Marine Science, 82, 315-331.

[30] United States National Oceanic and Atmospheric Administration (NOAA) (2001) Benthic habitats of Puerto Rico and the U.S. Virgin Islands. CD ROM, NOAA, National Ocean Service, National Centers for Coastal Ocean Science Biogeography Program, Silver Spring.

[31] CSA Group (2005) Evaluación, Delimitación y Análisis de los Usos en los Habitáculos Marinos Dentro de la Reserva Natural Arrecifes La Cordillera. Informe Final al Departamento de Recursos Naturales y Ambientales, 1-125.

[32] Departamento de Recursos Naturales y Ambientales (DRNA) (2007) Plan de Manejo de la Reserva Natural Arrecifes de La Cordillera, Fajardo. PR Department of Natural and Environmental Resources, San Juan, 1-88.

[33] Salm, R.V., Clark, J. and Siirila, E. (2000) Marine and Coastal Protected Areas: A Guide for Planners and Managers. 3rd Edition, International Union for the Conservation of Nature, Washington DC. http://dx.doi.org/10.2305/IUCN.CH.2000.13.en

[34] Russ, G.R. and Alcala, A.C. (1989) Effects of Intense Fishing Pressure on an Assemblage of Coral Reef Fishes. Marine Ecology Progress Series, 56, 13-27. http://dx.doi.org/10.3354/meps056013

[35] Scheffer, M., Carpenter, S. and De Young, B. (2005) Cascading Effects of Overfishing Marine Systems. Trends in Ecology and Evolution, 20, 579-581. http://dx.doi.org/10.1016/j.tree.2005.08.018

[36] Jones, E., Gray, T. and Umponstira, C. (2009) The Impact of Artisanal Fishing on Coral Reef Fish Health in Hat Thai Mueang, Phang-Nga Province, Southern Thailand. Marine Policy, 33, 544-552. http://dx.doi.org/10.1016/j.marpol.2008.12.003

[37] Stallings, C.D. (2009) Fishery-Independent Data Reveal Negative Effect of Human Population Density on Caribbean Predatory Fish Communities. PLoS ONE, 4, e5333. http://dx.doi.org/10.1371/journal.pone.0005333

[38] McManus, J.W., Meñez, L.A.B., Kesner-Reyes, K.N., Vergara, S.G. and Ablan, M.C. (2000) Coral Reef Fishing and Coral-Algal Phase Shifts: Implications for Global Reef Status. ICES Journal of Marine Science, 57, 572-578. http://dx.doi.org/10.1006/jmsc.2000.0720

[39] O’Leary, J.K., Potts, D.C., Braga, J.C. and McClanahan, T.R. (2012) Indirect Consequences of Fishing: Reduction of Coralline Algae Suppresses Juvenile Coral Abundance. Coral Reefs, 31, 547-559. http://dx.doi.org/10.1007/s00338-012-0872-5

[40] Rogers, C.S. and Miller, J. (2006) Permanent "Phase Shifts” or Reversible Declines in Coral Cover? Lack of Recovery of Two Coral Reefs in St. John, US Virgin Islands. Marine Ecology Progress Series, 306, 103-114. http://dx.doi.org/10.3354/meps306103

[41] Miller, J., Muller, E., Rogers, C., Waara, R., Atkinson, A., Whelan, K.R.T., Patterson, M. and Witcher, B. (2009) Coral Disease Following Massive Bleaching in 2005 Causes 60\% Decline in Coral Cover on Reefs in the US Virgin Islands. Coral Reefs, 28, 925-937. http://dx.doi.org/10.1007/s00338-009-0531-7

[42] Eakin, C.M., Morgan, J.A., Smith, T.B., Liu, G., Alvarez-Filip, L., Baca, B., Bouchon, C., Brandt, M., Bruckner, A., Cameron, A., Carr, L., Chiappone, M., James, M., Crabbe, C., Day, O., De la Guardia-Llanso, E., DiResta, D., Gilliam, D., Ginsburg, R., Gore, S., Guzmán, H., Hernández-Delgado, E.A., Husain, E., Jeffrey, C., Jones, R., Jordán-Dahlgren, E., Kramer, P., Lang, J., Lirman, D., Mallela, J., Manfrino, C., Maréchal, J.P., Mihaly, J., Miller, J., Mueller, E., Muller, E., Noordeloos, M., Oxenford, H., Ponce-Taylor, D., Quinn, N., Ritchie, K., Rodríguez, S., Rodríguez-Ramírez, A., Romano, S., Samhouri, J., Schmahl, G., Steiner, S., Taylor, M., Walsh, S., Weil, E. and Williams, E. (2010) Caribbean Corals in Crisis: Record Thermal Stress, Bleaching and Mortality in 2005. Plos ONE, 5, e13969. http://dx.doi.org/10.1371/journal.pone.0013969

[43] Hernández-Pacheco, R., Hernández-Delgado, E.A. and Sabat, A.M. (2011) Demographics of Bleaching in the Caribbean Reef-Building Coral Montastraea annularis. Ecosphere, 2, art9, 1-13. http://dx.doi.org/10.1890/ES10-00065.1

[44] Edmunds, P.J. (2013) Decadal-Scale Changes in the Community Structure of Coral Reefs of St. John, US Virgin Islands. Marine Ecology Progress Series, 489, 107-123. http://dx.doi.org/10.3354/meps10424

[45] Planque, B., Fromentin, J.M., Cury, P., Drinkwater, K.F., Jennings, S., Perry, R.I. and Kifani, S. (2010) How Does 
Fishing Alter Marine Populations and Ecosystems Sensitivity to Climate? Journal of Marine Systems, 79, 403-417. http://dx.doi.org/10.1016/j.jmarsys.2008.12.018

[46] Bellwood, D.R., Hughes, T.P., Folke, C. and Nyström, M. (2004) Confronting the Coral Reef Crisis. Nature, 429, 827833. http://dx.doi.org/10.1038/nature02691

[47] Hughes, T.P., Linares, C., Dakos, V., Van de Leemput, I.A. and Van Nes, E.H. (2013) Living Dangerously on Borrowed Time during Slow, Unrecognized Regime Shifts. Trends in Ecology and Evolution, 28, 149-155. http://dx.doi.org/10.1016/j.tree.2012.08.022

[48] Aronson, R.B., Macintyre, I.G., Precht, W.F., Murdoch, T.J.T. and Wapnick, C.M. (2002) The Expanding Scale of Species Turnover Events on Coral Reefs in Belize. Ecological Monographs, 72, 233-249. http://dx.doi.org/10.1890/0012-9615(2002)072[0233:TESOST]2.0.CO;2

[49] Graham, N.A.J., Bellwood, D.R., Cinner, J.E., Hughes, T.P., Norström, A.V. and Nyström, M. (2013) Managing Resilience to Reverse Phase Shifts in Coral Reefs. Frontiers in Ecology and Environment, 11, 541-548. http://dx.doi.org/10.1890/120305

[50] Williams, I.D. and Polunin, N.V.C. (2000) Differences between Protected and Unprotected Reefs of the Western Caribbean in Attributes Preferred by Dive Tourists. Environmental Conservation, 27, 382-391. http://dx.doi.org/10.1017/S0376892900000436

[51] Agardy, T. (2000) Information Needs for Marine Protected Areas: Scientific and Societal. Bulletin of Marine Science, 66, $875-888$

[52] Bunce, L., Gustavson, K., Williams, J. and Miller, M. (1999)The Human Side of Reef Management: A Case Study Analysis of the Socioeconomic Framework of Montego Bay Marine Park. Coral Reefs, 18, 369-380. http://dx.doi.org/10.1007/s003380050215

[53] Kelleher, G. (1999) Guidelines for Marine Protected Areas. International Union for the Conservation of Nature, Gland, Switzerland.

[54] National Research Council (NRC) (2001) Marine Protected Areas: Tools for Sustaining Marine Ecosystems. National Academy Press, Washington DC.

[55] Suman, D.O., Shivlani, M.P. and Milon, J.W. (1999) Perceptions and Attitudes Regarding Marine Reserves: A Comparison of Stakeholder Groups in the Florida Keys National Marine Sanctuary. Ocean and Coastal Management, 42, 1019-1040. http://dx.doi.org/10.1016/S0964-5691(99)00062-9

[56] Weible, C.M. (2008) Caught in a Maelstrom: Implementing California Marine Protected Areas. Coastal Management, 36, 350-373. http://dx.doi.org/10.1080/08920750802266387

[57] Murray, T.J. and Associates (2007) Socio-Economic Baseline Development: Florida Keys National Marine Sanctuary, Fishing Years 1998-2006. http://sanctuaries.noaa.gov/science/socioeconomic/floridakeys/pdfs/commfishpan7and8.pdf

[58] Day, J. (2008) The Need and Practice of Monitoring, Evaluating and Adapting Marine Planning and ManagementLessons from the Great Barrier Reef. Marine Policy, 32, 823-831. http://dx.doi.org/10.1016/j.marpol.2008.03.023

[59] Shivlani, M. (2008) Characterization of Stakeholder Uses in Marine Protected Areas in Support of Establishing Limits of Acceptable Change: Five Case Studies in the Coastal and Marine Natural Reserve System of Puerto Rico. Unpublished Manuscript.

[60] Helvey, M. (2004) Seeking Consensus on Designing Marine Protected Areas: Keeping the Fishing Community Engaged. Coastal Management, 32, 173-190. http://dx.doi.org/10.1080/08920750490276236

[61] Weible, C., Sabatier, P.A. and Lubell, M. (2004) A Comparison of a Collaborative and Top-Down Approach to the Use of Science in Policy: Establishing Marine Protected Areas in California. The Policy Studies Journal, 32, 187-207. http://dx.doi.org/10.1111/j.1541-0072.2004.00060.x

[62] Valdés-Pizzini, M. (1990) Fishermen Associations in Puerto Rico: Praxis and Discourse in the Politics of Fishing. Human Organizations, 49, 164-173.

[63] National Academy of Public Administration (NAPA) (2000) Protecting our National Marine Sanctuaries: A Report by the Center for the Economy and the Environment. NAPA, Washington DC.

[64] Delaney, J.M. (2003) Community Capacity Building in the Designation of the Tortugas Ecological Reserve. Gulf and Caribbean Research, 14, 163-169.

[65] Walmsley, S.F. and White, A.T. (2003) Influence of Social, Management and Enforcement Factors on the Long-Term Ecological Effects of Marine Sanctuaries. Environmental Conservation, 30, 388-407. http://dx.doi.org/10.1017/S0376892903000407

[66] McConney, P., Pomeroy, R. and Mahon, R. (2003) Guidelines for Coastal Resource Co-Management in the Caribbean: Communicating the Concepts and Conditions that Favour Success. Caribbean Coastal Co-Management Guidelines Project. Caribbean Conservation Association, Barbados, 1-56. 
[67] Naumann, S., Davis, M., Munang, R., Andrews, J., Thiaw, I., Alverson, K., Mumba, M., Kavag, L. and Han, Z. (2013) The Social Dimension of Ecosystem-Based Adaptation. Policy Brief 12, United Nations Environment Program, New York.

[68] Badalamenti, F., Ramos, A.A., Voultsiadou, E., Sánchez-Lizaso, J.L., D’Anna, G., Pipitone, C., Mas, J., Ruiz-Fernández, J.A., Whitmarsh, D. and Riggio, S. (2000) Cultural and Socio-Economic Impacts of Mediterranean Marine Protected Areas. Environmental Conservation, 27, 110-125. http://dx.doi.org/10.1017/S0376892900000163

[69] Graham, N.A.J., Cinner, J.E., Norström, A.V. and Nyström, M. (2014) Coral Reefs as Novel Ecosystems: Embracing New Futures. Current Opinion in Environmental Sustainability, 7, 9-14. http://dx.doi.org/10.1016/j.cosust.2013.11.023

[70] Hernández-Delgado E.A., Ramos-Scharrón, C.E., Guerrero, C., Lucking, M.A., Laureano, R., Méndez-Lázaro, P.A. and Meléndez-Díaz, J.O. (2012) Long-Term Impacts of Non-Sustainable Tourism and Urban Development in Small Tropical Islands Coastal Habitats in a Changing Climate: Lessons Learned from Puerto Rico. In: Kasimoglu, M., Ed., Visions for Global Tourism Industry-Creating and Sustaining Competitive Strategies, InTech Publications, Rijeka, 357-398.

http://www.intechopen.com/books/visions-for-global-tourism-industry-creating-and-sustaining-competitive-strategies/l ong-term-impacts-of-non-sustainable-tourism-and-urban-development-in-tropical-coastal-habitats-in-a

[71] Rogers, C.S. (1990) Responses of Coral Reefs and Reef Organisms to Sedimentation. Marine Ecology Progress Series, 62, 185-202. http://dx.doi.org/10.3354/meps062185

[72] Nowlis, J.S., Roberts, C.M., Smith, A.H. and Siirila, E. (1997) Human-Enhanced Impacts of a Tropical Storm on Nearshore Coral Reefs. AMBIO, 26, 515-521.

[73] Larsen, M.C. and Webb, R.M.T. (2009) Potential Effects of Runoff, Fluvial Sediment, and Nutrient Discharges on the Coral Reefs of Puerto Rico. Journal of Coastal Research, 25, 189-208. http://dx.doi.org/10.2112/07-0920.1

[74] Ramos-Scharrón, C.E., Amador, J.M. and Hernández-Delgado, E.A. (2012) An Interdisciplinary Erosion Mitigation Approach for Coral Reef Protection-A Case Study from the Eastern Caribbean. In: Cruzado, A., Ed., Marine Ecosystems, InTech Publications, Rijeka, 127-160.

http://www.intechopen.com/articles/show/title/an-interdisciplinary-erosion-mitigation-approach-for-coral-reef-protecti on-a-case-study-from-the-eas 
Scientific Research Publishing (SCIRP) is one of the largest Open Access journal publishers. It is currently publishing more than 200 open access, online, peer-reviewed journals covering a wide range of academic disciplines. SCIRP serves the worldwide academic communities and contributes to the progress and application of science with its publication.

Other selected journals from SCIRP are listed as below. Submit your manuscript to us via either submit@scirp.org or Online Submission Portal.
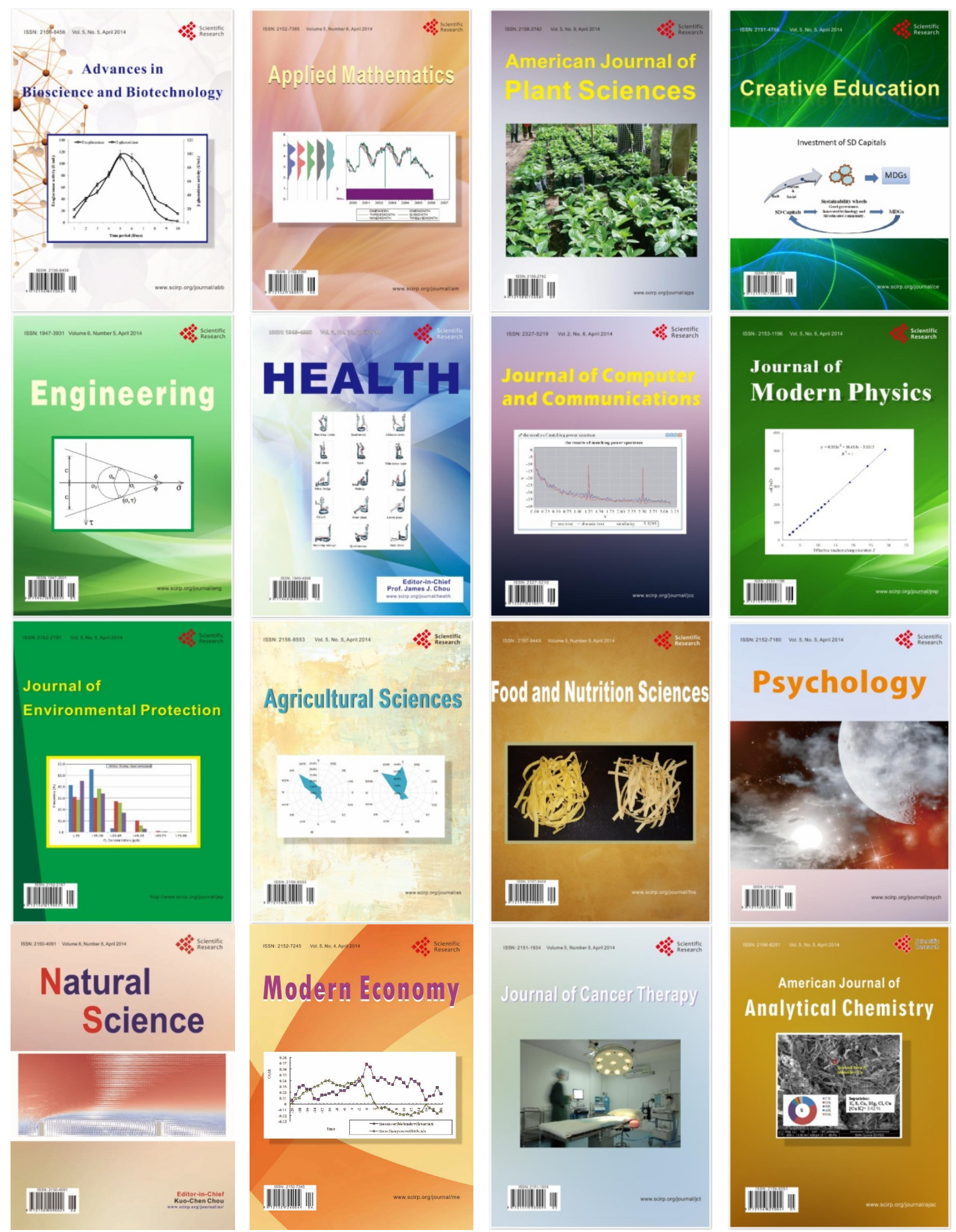